\title{
Efficient and Stable Blue- and Red-Emitting Perovskite Nanocrystals through Defect Engineering: $\mathrm{PbX}_{2}$ Purification
}

ChaeHyun Lee, YeJi Shin, Alexis Villanueva-Antolí, Samrat Das Adhikari, Jhonatan Rodriguez-Pereira, Jan M. Macak, Camilo A. Mesa, Sixto Giménez, Seog Joon Yoon,* Andrés. F. Gualdrón-Reyes,* and Iván Mora-Seró*

Cite This: Chem. Mater. 2021, 33, 8745-8757

Read Online

ACCESS | 네 Metrics \& More | 回 Article Recommendations | sl Supporting Information

ABSTRACT: Current efforts to reduce the density of structural defects such as surface passivation, doping, and modified synthetic protocols have allowed us to grow high-quality perovskite nanocrystals (PNCs). However, the role of the purity of the precursors involved during the PNC synthesis to hinder the emergence of defects has not been widely explored. In this work, we analyzed the use of different crystallization processes of $\mathrm{PbX}_{2}\left(\mathrm{X}=\mathrm{Cl}^{-}\right.$or $\left.\mathrm{I}^{-}\right)$to purify the chemicals and produce highly luminescent and stable $\mathrm{CsPbCl} \mathrm{Pb}_{3-x} \mathrm{Br}_{x}$ and

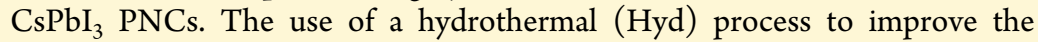
quality of the as-prepared $\mathrm{PbCl}_{2}$ provides blue-emitting PNCs with efficient ligand surface passivation, a maximum photoluminescence quantum yield (PLQY) of $\sim 88 \%$, and improved photocatalytic activity to oxidize benzyl

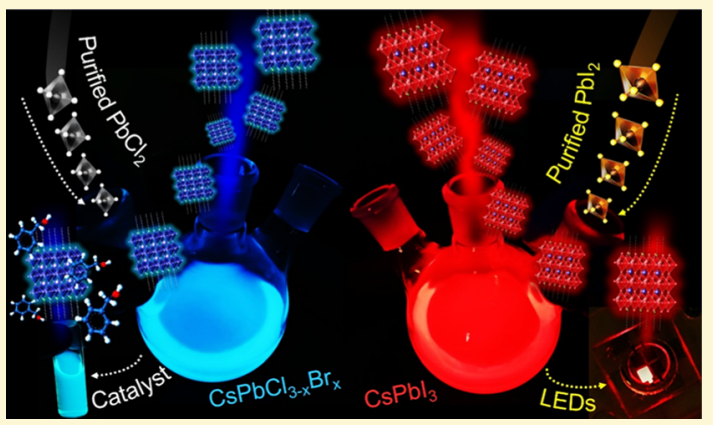
alcohol, yielding $40 \%$. Then, the hot recrystallization of $\mathrm{PbI}_{2}$ prior to $\mathrm{Hyd}$ treatment led to the formation of red-emissive PNCs with a PLQY of up to 100\%, long-term stability around 4 months under ambient air, and a relative humidity of $50-60 \%$. Thus, $\mathrm{CsPbI}_{3}$ light-emitting diodes were fabricated to provide a maximum external quantum efficiency of up to $13.6 \%$. We claim that the improvement of the $\mathrm{PbX}_{2}$ crystallinity offers a suitable stoichiometry in the PNC structure, reducing nonradiative carrier traps and so maximizing the radiative recombination dynamics. This contribution gives an insight into how the manipulation of the $\mathrm{PbX}_{2}$ precursor is a profitable and potential alternative to synthesize $\mathrm{PNCs}$ with improved photophysical features by making use of defect engineering.

\section{INTRODUCTION}

Attending to the growing interest in nanomaterials for actively studying renewable energy research fields including photovoltaics, optoelectronics, photonics, and solar-driven chemistry, halide perovskite nanocrystals (PNCs) have recently been established as attractive semiconductor materials. ${ }^{1}$ Among their most notable characteristics include (i) their relatively easy preparation, (ii) narrow width at half-maximum photoluminescence (PL) peak, ${ }^{2}$ (iii) an adjustable/modifiable surface chemistry, ${ }^{3,4}$ (iv) a notable PL quantum yield (PLQY) of up to $100 \%,{ }^{5-8}$ and (v) a modulable band gap $\left(\mathrm{E}_{\mathrm{g}}\right)$ by varying the PNC size due to the quantum confinement effect, composition of A-site cations (e.g., formamidinium cation, $\mathrm{Cs}^{+}$), or $\mathrm{X}$-site halides in the $\mathrm{ABX}_{3}$-type perovskites, $^{9-11}$ taking into account that phase photosegregation in mixed-halide PNCs is restricted in comparison with their bulk counterparts. ${ }^{12}$ These intrinsic features have been exploited to fabricate efficient PNC solar cells ${ }^{13}$ with a high photoconversion efficiency of up to $18.1 \%,{ }^{14}$ light-emitting diodes (LEDs) with external quantum efficiencies (EQEs) surpassing 20\%, ${ }^{15,16}$ scintillators, ${ }^{17}$ photodetectors, ${ }^{18}$ light amplifiers, ${ }^{19}$ lasers, ${ }^{20}$ and solar concentrators ${ }^{21}$ among others. Despite the benign defect physics of halide perovskites, the
PLQY is limited by the defective structure, which in addition makes them prone to degradation. ${ }^{22,23}$ Two pivotal factors are responsible to generate structural defects into PNCs: (i) the synthetic protocols for the PNC growth and (ii) the loss of capping ligands to hinder their stabilization. ${ }^{8,24}$ In both cases, halide vacancies emerge as the main defects into the perovskite structure, $^{25}$ causing the appearance of a high density of nonradiative recombination sites. ${ }^{26}$ Consequently, the radiative channel of excitons is reduced, limiting the PLQY, the stability of the final product, and the effective extraction of carriers. ${ }^{27,28}$

Various efforts have been carried out to produce lessdefective PNCs with enhanced intrinsic properties and structural integrity. Most of the reports have emphasized on the purification of the as-prepared material by using polar/ nonpolar antisolvents, ${ }^{24,29}$ the addition of organic ligands with strong binding capability to the perovskite surface, ${ }^{30-32}$ the use

Received: August 11, 2021

Revised: September 27, 2021

Published: November 11, 2021 
of metal halide/thiocyanate/fluoroborate salts, ${ }^{33,34}$ or cation/ anion doping. ${ }^{35,36}$ In general, these strategies aim at favoring a suitable ligand passivation of the material surface by filling both the halide and cation deficiency and also by repairing the damage induced by the existence of defect centers, mainly removing undercoordinated species as metallic lead $\left(\mathrm{Pb}^{0}\right){ }^{8}$ While it is true that the above-mentioned strategies are applicable to a broad range of PNCs (organic/inorganic, different halide compositions), it is also clear that most of these approaches have been focused toward green-emitting $\mathrm{APbBr}_{3}$ PNCs $\left(\mathrm{A}=\mathrm{Cs}^{+}\right.$and $\mathrm{FA}^{+}$; formamidinium $),{ }^{8}$ obtaining remarkable results in the preparation of high-quality materials with improved PL properties. ${ }^{37}$ In this context, it seems that the defective surface of chloride- and iodide-PNCs cannot be completely restored or fixed through the above strategies in the same way to that of the bromide-PNCs, which accelerate the eventual loss of their photophysical features and the degradation of the material. This discrepancy can be explained in terms of the degree of defect tolerance from halide-PNCs and the difficulty of passivating/filling these defects for improving the quality of band edge emission. In the case of $\mathrm{CsPbCl}, \mathrm{Cl}^{-}$vacancies are deep states localized into the midband gap, inducing a strong $\left[\mathrm{PbCl}_{6}\right]$ octahedra distortion, which deteriorates the phase stability and decreases the radiative-to-nonradiative recombination rate constant ratio $\left(k_{\mathrm{r}} / k_{\mathrm{nr}}\right) .{ }^{35,38}$ Thus, only a $5 \%$ of traps into Cl-PNCs can yield PLQY values $<20 \%$. $^{38}$ In this way, the incorporation of $\mathrm{M}^{y+} \mathrm{Cl}_{y}\left(\mathrm{M}^{y+}=\mathrm{Ni}^{2+}, \mathrm{Cu}^{2+}, \mathrm{Cd}^{2+}\right.$, and $\left.\mathrm{Y}^{3+}\right)$ is reported to minimize the $\mathrm{Cl}^{-}$deficiency and restrain the octahedra distortion, which have allowed to reach PLQY values of 60-96\%. ${ }^{35,39-41}$

On the other hand, halide vacancies formed in $\mathrm{Br}$ - and IPNCs are recognized as shallow states rather than being located in the midband gap, making the trap-assisted radiative recombination less effective than Cl-PNCs (larger $k_{\mathrm{r}} / k_{\mathrm{nr}}$ ). ${ }^{6,38}$ Nevertheless, due to the lower complexation affinity of the $\mathrm{Pb}-\mathrm{I}$ bond compared to that of the $\mathrm{Pb}-\mathrm{Br}$ bond, ${ }^{42,43}$ iodide anions are more prone to be detached from the PNCs, favoring the damage of $\left[\mathrm{PbI}_{6}\right]$ octahedra units. ${ }^{44}$ To solve this issue, we have shown that the increase of the capping ligand content during the synthesis can improve the $\mathrm{PbI}_{2}$ stabilization, providing more iodide species to be consumed for PNC growth. $^{45}$ This fact enhances the ligand passivation of the PNC surface. A PLQY of around $93 \%$ for $\mathrm{CsPbI}_{3} \mathrm{PNCs}$ was achieved, with a long-term stability around 15 months. Similarly, the Sr-doping of $\mathrm{FAPbI}_{3}$ PNCs has allowed to evidence the successful formation of a less halide-defective three-dimensional (3D) perovskite structure with a PLQY of $100 \%$ and stability for 8 months. ${ }^{5}$ Also, purification of the $\mathrm{PbI}_{2}$ precursor leads to a positive effect to increase the photovoltaic performance of methylammonium lead iodide $\left(\mathrm{MAPbI}_{3}\right)$ solar cells by increasing the iodine component. ${ }^{46}$ At this point, the nature and quality of the halide source exhibit an effect on the synthesis of PNCs with a highly tolerant-to-defect crystal structure, which has not been exploited in depth. The recent literature has reported that the use of low-purity $\mathrm{PbX}_{2}$ (mostly $\mathrm{PbI}_{2}$ ) promotes the synthesis of perovskites with high density of defects due to the presence of impurities and halide deficiency in the halide precursor. These species act as nonradiative carrier traps into the perovskite material, deteriorating its $\mathrm{PL}$ properties and impacting negatively on the device performance. Thus, high-purity $\mathrm{PbX}_{2}$ precursors are preferred to produce perovskites with improved photophysical features to be more adequate in the fabrication of devices with high performance, as the case of solar cells. ${ }^{47,48}$ However, these precursors are expensive, increasing the production cost, and in some cases, they do not compensate completely the stoichiometry of the final product. Considering that the purity degree of the $\mathrm{PbX}_{2}$ precursor is pivotal to dictate the quality of the perovskite, it is reasonable that low-purity $\mathrm{PbX}_{2}$ can be modified before the use in synthesis, with the purpose to reduce the halide deficiency and provide lesser defective perovskites and improve their potentiality in hot-topic applications.

In this work, we studied the influence of the different recrystallization methods of the as-synthesized and commercially available $\mathrm{PbX}_{2}$ precursors on the defect-mediated nonradiative recombination process, chemical environment, and the optical performance of $\mathrm{CsPbCl}_{3-x} \mathrm{Br}_{x}$ and $\mathrm{CsPbI}_{3}$ PNCs. We demonstrated that the use of recrystallization and hydrothermal processes improves the quality of $\mathrm{PbCl}_{2}$ and $\mathrm{PbI}_{2}$ to generate (i) blue-emitting PNCs with efficient surface passivation, a PLQY of $\sim 88 \%$, and a high photocatalytic activity for benzyl alcohol oxidation of $\sim 40 \%$. Furthermore, (ii) highly red-emissive PNCs with $\sim 100 \%$ PLQY and longterm stability around 4 months under air conditions were obtained to fabricate $\mathrm{CsPbI}_{3}$-LEDs with an EQE of up to $13.6 \%$. By controlling the crystallinity of the halide source through the above-mentioned processes, defect engineering is established to provide a suitable stoichiometry and increase the density of the halide into $\mathrm{PbX}_{2}$. Hence, more $\mathrm{X}^{-}$anions are available to mediate the synthesis of less-halide-defective PNCs with enhanced photophysical properties and carrier transport ability. This contribution successfully exploits the modulation of defect density into $\mathrm{PbX}_{2}$ precursors as a valuable strategy to synthesize PNCs with a better defect-tolerant crystal structure, high optical performance to be applied in solar-driven processes, and the fabrication of efficient optoelectronic devices.

\section{RESULTS AND DISCUSSION}

Considering the impact of halides on PNC defects, we aimed at elucidating the role of halide precursor quality on the photophysical properties of PNCs. From earlier works, crystallization and purification are key processes to eliminate impurities and provide a better stoichiometric ratio of the perovskite components. ${ }^{46}$ Therefore, we improved the quality of $\mathrm{PbI}_{2}$ and $\mathrm{PbCl}_{2}$ by synthesizing the halide precursor through precipitation (referred to as the as-prepared, AP) and then recrystallized by conducting a rapid cooling (cold-recrystallization, CR) or mild cooling (cooling solution in water bath, temperature starts at $70{ }^{\circ} \mathrm{C}$, named as hot-recrystallization, HR). Last, halide salts were purified by performing the consecutive hydrothermal process (Hyd). The preparation/ recrystallization process of $\mathrm{PbX}_{2}$ was modified by "Golden Rain" methods provided by the Royal Society of Chemistry. ${ }^{49}$ Precipitation reaction schemes of $\mathrm{PbI}_{2}$ and $\mathrm{PbCl}_{2}$ are presented in Supporting Information, page 2. X-ray diffraction (XRD) patterns of $\mathrm{PbX}_{2}$ in Figure $\mathrm{S} 1$ support the formation of $\mathrm{PbCl}_{2}$ and $\mathrm{PbI}_{2}$ without the presence of impurities after reaction/ recrystallization/hydrothermal processes to purify the crude $\mathrm{PbX}_{2}$, being identical to the commercial (Com-) halide precursor. Then, considering the different treatments for purifying the halide precursors, $\mathrm{CsPbCl}_{3-x} \mathrm{Br}_{x}$ mixed-halide PNCs (MHPs) are named as Com-, AP-, Hyd-Com-, and HydAP-MHPs, while (ii) $\mathrm{CsPbI}_{3}$ PNCs (CsPI) are called as Com-, 


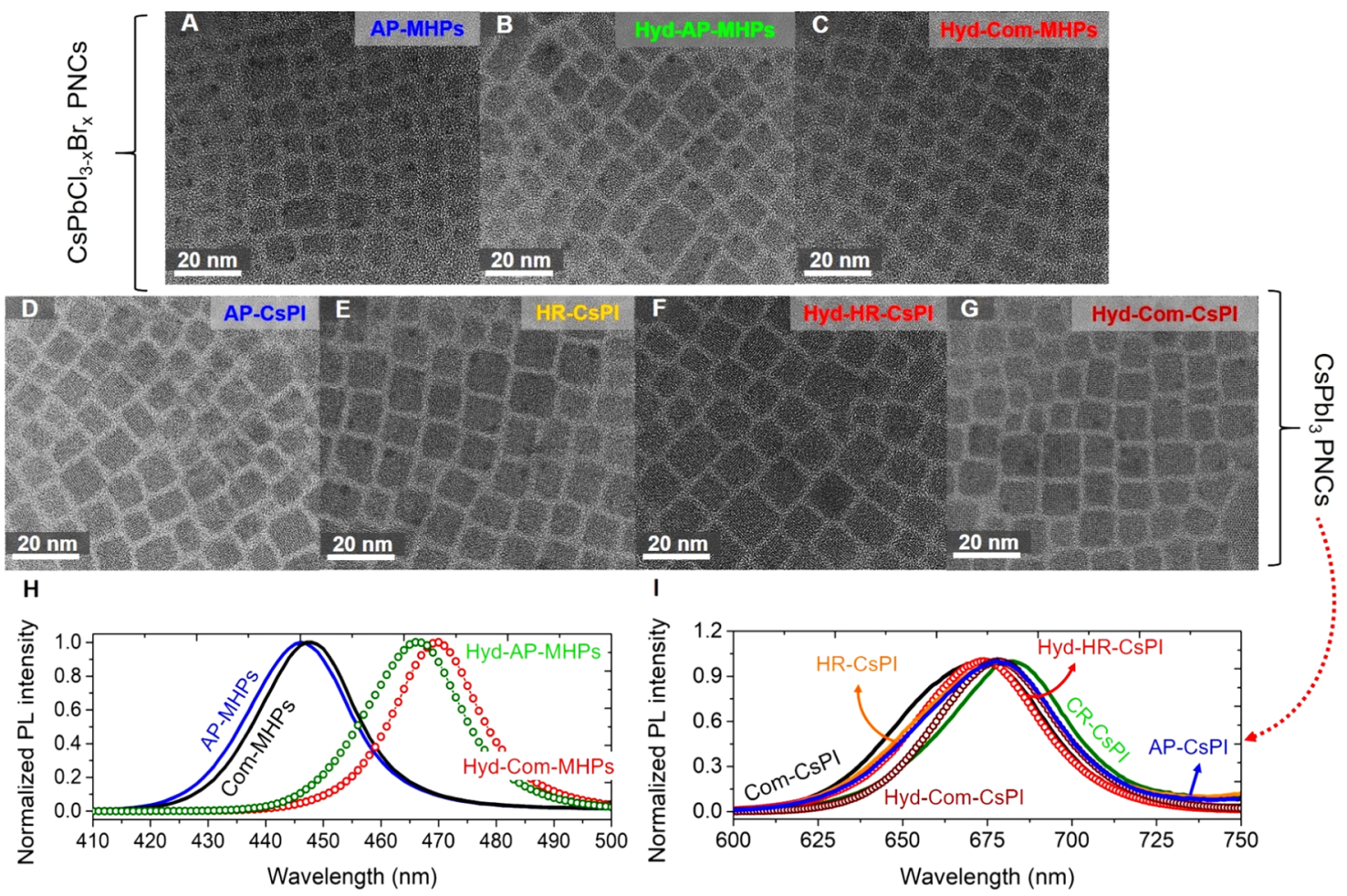

Figure 1. (A-G) Typical TEM images and (H,I) PL spectra of (A-C,H) MHPs and (D-G,I) CsPI PNCs synthesized with different crystallized and purified $\mathrm{PbCl}_{2}$ and $\mathrm{PbI}_{2}$ precursors, respectively.

AP-, CR-, HR-, Hyd-Com-, and Hyd-HR-CsPI for comparative purposes.

Figure 1 shows the typical transmission electron microscopy (TEM) images of $\mathrm{CsPbCl}_{3-x} \mathrm{Br}_{x}(\mathrm{~A}-\mathrm{C})$ and $\mathrm{CsPbI}_{3} \mathrm{PNCs}$ (D-G) obtained by using different $\mathrm{PbCl}_{2}$ and $\mathrm{PbI}_{2}$ precursors during hot-injection synthesis. Com-MHPs and Com-CsPI are presented in Figure S2. All the blue-emitting PNC samples exhibit a nanocube morphology, with an average particle size between 7.7 and $10 \mathrm{~nm}$. It was also observed that the particle size of Hyd-AP- and Hyd-Com-MHPs was higher, accompanied with an increase of the bromine content deduced from energy-dispersive X-ray spectroscopy (Table S1). In the case of red-emitting PNCs, the change of particle size was less pronounced (around 10-11.1 nm), also detecting variations on their stoichiometry (Table S2). These materials undergo the quantum confinement regime since the Bohr diameter for $\mathrm{CsPbI}_{3}$ is around $12 \mathrm{~nm}$. ${ }^{9}$ The corresponding size distribution calculated for these materials is shown in Figure S3A-J. Then, Figure $S 4$ presents the XRD patterns obtained for $\mathrm{CsPbCl}_{3-x} \mathrm{Br}_{3}$ and $\mathrm{CsPbI}_{3}$ PNC samples to observe the effect of the crystallization and purification of $\mathrm{PbX}_{2}$ on the structural features of the nanocrystals. At this point, the shift of XRD peaks to lower Bragg angles in the MHPs implies an expansion of the perovskite lattice, associated to the enlargement of $\mathrm{Pb}-$ $\mathrm{X}$ by increasing the ionic radius of the halide $\left(\mathrm{Br}^{-}>\mathrm{Cl}^{-}\right){ }^{50}$ This indicates that the Hyd purification of Com- and $\mathrm{AP}-\mathrm{PbCl}_{2}$ salts promotes the incorporation of more $\mathrm{Br}^{-}$domains into MHPs. On the other hand, by conducting selected area electron diffraction (SAED) in MHP samples (Figure S5A$D)$, we were able to identify the representative interplanar spacings of both types of PNCs, corresponding to the cubic phase (ICSD 29073) from the perovskite structure. ${ }^{51}$ This feature is different from a $\mathrm{CsPbBr} 3$ PNC as a reference, where the orthorhombic phase is the preferred crystalline structure (ICSD 97851).

By considering that all the $\mathrm{CsPbCl}_{3-x} \mathrm{Br}_{x}$ samples were synthesized with a nominal $\mathrm{Cl} / \mathrm{Br}$ ratio $=1: 1(x=1.5)$, we suggest that the alteration of the halide stoichiometry is mediated by the ability of $\mathrm{PbCl}_{2}$ to be dissolved during the nanocrystal synthesis. As reported previously, the addition of trioctylphosphine into the mixture reaction is pivotal to mediate the $\mathrm{PbCl}_{2}$ dissolution and stabilize Cl-PNCs. ${ }^{9,10}$ Then, it has also been shown that the Hyd process can decrease the defects existing in the $\mathrm{PbX}_{2}$ precursors, particularly halide vacancies, improving the salt crystallinity. ${ }^{46}$ Accordingly, we propose that the emergence of more $\mathrm{Pb}-\mathrm{Cl}$ bonds by filling $\mathrm{Cl}$ vacancies during $\mathrm{Hyd}$ purification hinders the $\mathrm{PbCl}_{2}$ dissolution due to the high $\mathrm{Pb}-\mathrm{Cl}$ complexation affinity. ${ }^{52}$ Thus, more $\mathrm{Br}^{-}$species from $\mathrm{PbBr}_{2}$ can supply the halide positions of the MHPs. For the case of $\mathrm{CsPbI}_{3}$ PNCs, samples also show the typical XRD profile of the cubic phase (ICSD 161481). ${ }^{53}$ Nevertheless, CR-CsPI depicts a displacement of XRD patterns to higher Bragg angles compared to the other materials, associated to the emergence of a tetragonal crystalline structure (ICSD 69995). ${ }^{54}$ This fact is also corroborated through SAED patterns obtained for these materials (Figure S5E-J). In this line, it has been reported that nanoconfinement of $\mathrm{CsPbI}_{3} \mathrm{PNCs}$ restrains the octahedra tilting, stabilizing the photoactive black cubic $\alpha$-phase. However, by increasing the particle size, the corner-sharing $\left[\mathrm{PbI}_{6}\right]$ octahedra can be distorted, breaking the cubic symmetry to achieve the tetragonal $\beta$-phase or orthorhombic $\gamma$-phase. ${ }^{54}$ This structural alteration is favored by the small size of $\mathrm{Cs}^{+}$cations occupying the A-site in the perovskite lattice, requiring a strong tensile strain to retain the cubic geometry. ${ }^{54}$ Thus, it is deductible that the absence of $\mathrm{Cs}^{+}$in PNCs would facilitate even more this change of the phase. Since CR-CsPI 
A

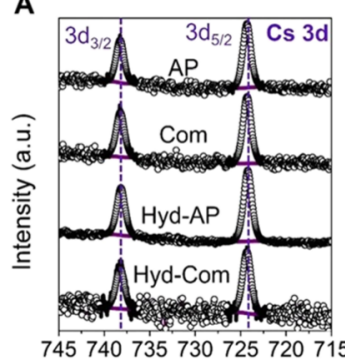

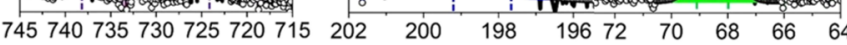
Binding energy (eV)

$\mathbf{A}^{\prime}$

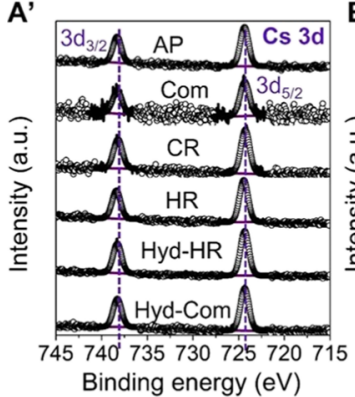

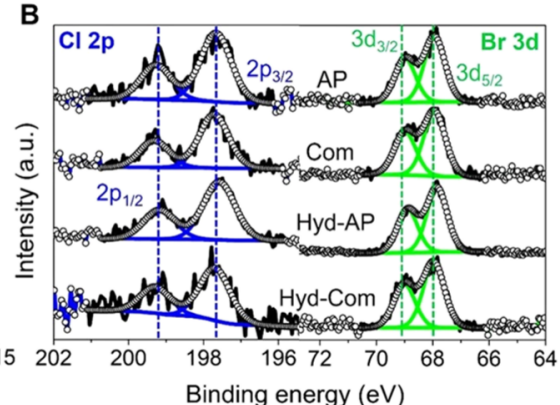

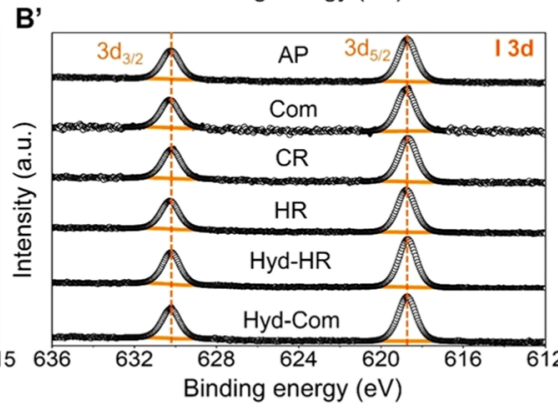

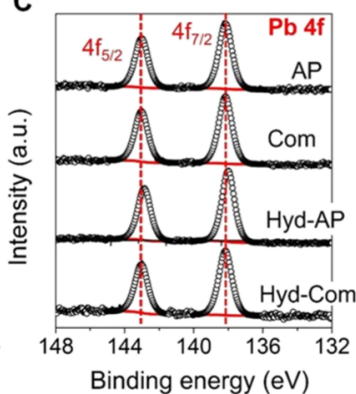

$C^{\prime}$

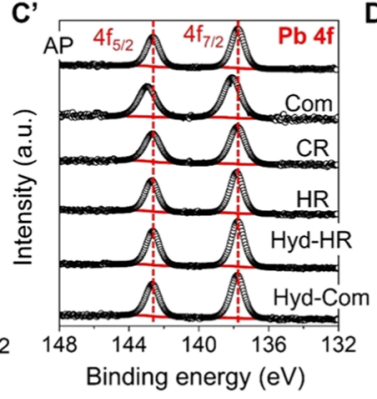

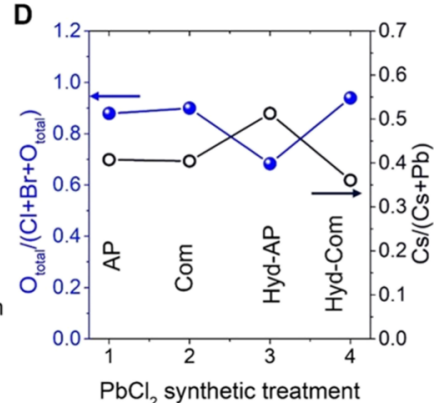

D'

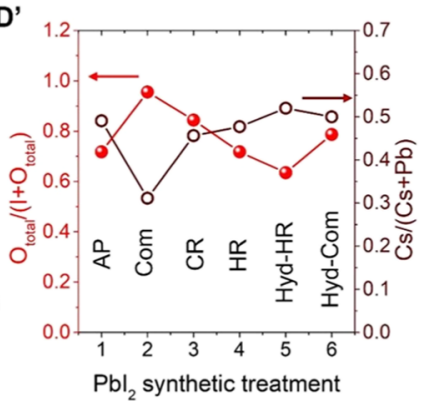

Figure 2. HR XPS (A, $\left.\mathrm{A}^{\prime}\right) \mathrm{Cs} 3 \mathrm{~d},(\mathrm{~B}) \mathrm{Cl} 2 \mathrm{p}-\mathrm{Br} 3 \mathrm{~d},\left(\mathrm{~B}^{\prime}\right) \mathrm{I} 3 \mathrm{~d},\left(\mathrm{C}, \mathrm{C}^{\prime}\right) \mathrm{Pb} 4 \mathrm{f}$ spectra, and $\left(\mathrm{D}, \mathrm{D}^{\prime}\right)$ calculated oxygen-to-halide/Cs-to-total metal ratios for $(\mathrm{A}-\mathrm{D}) \mathrm{MHPs}$ and $\left(\mathrm{A}^{\prime}-\mathrm{D}^{\prime}\right)$ CsPI PNCs synthesized with different crystallized and purified $\mathrm{PbCl}_{2}$ and $\mathrm{PbI}_{2}$ precursors, respectively.

displays the lowest $\mathrm{Cs} / \mathrm{Pb}$ ratio (Table $\mathrm{S} 2$ ), we suggest that this defect grade is the threshold to promote the octahedral distortion into $\mathrm{CsPbI}_{3}$ to provide the $\alpha$-to- $\beta$-phase transformation.

The effect of $\mathrm{PbX}_{2}$ purification was also observed through changes of the optical properties of $\mathrm{CsPbCl}_{3-x} \mathrm{Br}_{x}$ and $\mathrm{CsPbI}_{3}$ PNCs. The corresponding optical features of the samples are exhibited in Table S3. The MHPs present a redshift in the PL peak (Figure $1 \mathrm{H}$ ) and absorption onset (Figure S6A) after conducting the Hyd treatment, attributed to the band gap narrowing. This result agrees well with the increase of the bromine content, ${ }^{50}$ see Table S1. In addition, the particle size for $\mathrm{CsPbCl}_{3-x} \mathrm{Br}_{x}$ also increases, see Figure S3. Then, by comparing the PL intensity obtained for MHPs under the same colloidal solution concentration $\left(2.0 \mathrm{mg} \mathrm{mL}^{-1}\right.$ ) (Figure $\mathrm{S}^{\prime} \mathrm{A}^{\prime}$ ), Hyd-AP-MHPs displayed the highest PL signal, followed by Hyd-Com-MHPs. The PL improvement indicates that the application of the $\mathrm{Hyd}$ process to $\mathrm{PbCl}_{2}$ prepared by the precipitation method enhances the radiative recombination due to the enhanced crystallinity of the precursor, commonly associated to the reduction of nonradiative carrier traps. ${ }^{55}$

On the other hand, analyzing the optical features of $\mathrm{CsPbI}_{3}$ PNCs, we evidenced that the PL peak position (Figure 1I) and the respective absorption band onset (Figure S6B) of AP-, CR-, HR-, and Hyd-Com-CsPI were slightly redshifted. This fact is an indication of the band gap narrowing caused by the weakening of the quantum confinement due to the increase of the particle size, ${ }^{45}$ as shown in TEM images (Figures $1 D-G$ and $S 3 E-G$ ). Since $C R, H R$, and Hyd processes can enhance the quality of the $\mathrm{PbI}_{2}$ precursor by compensating iodide defects, we infer that more iodine is able to participate in the reaction medium to grow bigger nanocrystals. However, the appearance of structural defects such as $\mathrm{Cs}^{+}$and $\mathrm{I}^{-}$vacancies could affect its growth and stabilization. During PNC synthesis, oleylammonium cations bounded to iodide (OLAm-I) can simultaneously fill $\mathrm{Cs}^{+}$positions, stabilizing the perovskite structure. ${ }^{56}$ Unfortunately, the washing process of PNCs can detach some OLAm-I from the nanocrystal surface, leaving $\mathrm{Cs}^{+}$and $\mathrm{I}^{-}$vacancies, which promotes the material growth. ${ }^{57}$ This fact can explain the formation of the biggest PNC size for CR-CsPI, providing a redshift in their absorption/PL features (Table S4). Conversely, the emission peak and absorption edge of Hyd-HR-CsPI were not displaced as much as the other materials due to a lower iodide content to limit the PNC growth. Nevertheless, this material exhibits the most suitable stoichiometry, which is vital for improving the photophysical properties. Hyd-HR-CsPI exhibited the highest $\mathrm{PL}$ intensity, followed by Hyd-Com-CsPI (Figure S6B'), allowing us to further corroborate that the Hyd purification of $\mathrm{PbX}_{2}$ generates a lesser-defective halide precursor to synthesize high-quality PNCs with improved optical properties.

By comparing the PL features of blue- and red-emitting PNCs, it is evident that the emission intensity of Hyd-CsPI samples is at least 2-order magnitude higher compared to that of Hyd-MHP, see Figure S6. This is reasonable since Cl-PNCs are more prone to present deep trap energy levels into their wider band gap, being these states the primary nonradiative recombination sites. ${ }^{38,58}$ With the purpose for improving the PL features of the Hyd-treated MHP samples keeping almost unaltered their blue-light emission, we have added a low amount of didodecyldimethylammonium bromide (DDAB) to the colloidal solutions (100 $\mu \mathrm{L}, 12.5 \mathrm{mM}$ DDAB in toluene) and measured again their corresponding PL spectra. DDAB is used in the ligand passivation process of PNCs by (i) filling $\mathrm{Br}^{-}$species into the halide vacancies from $\mathrm{PbX}_{6}$ octahedra, while (ii) $\mathrm{DDA}^{+}$cations show a high binding capability to $\mathrm{Br}$ domains or adsorbed $\mathrm{Br}^{-}$species from the PNC surface. ${ }^{31,59}$ As seen in Figure S7, Hyd-AP- and Hyd-Com-MHPs display a redshift from their nonmodified counterparts and a significant increase of the emission intensity, associated to the incorporation of $\mathrm{Br}^{-}$species from DDAB. ${ }^{59}$ This suggests that these materials show a low content of surface defects to be filled, providing a more efficient radiative recombination channel. At this stage, we found suitable the incorporation of DDAB to improve the photophysical properties of Hyd-treated MHPs, mainly PLQY, and support the modulation of their 

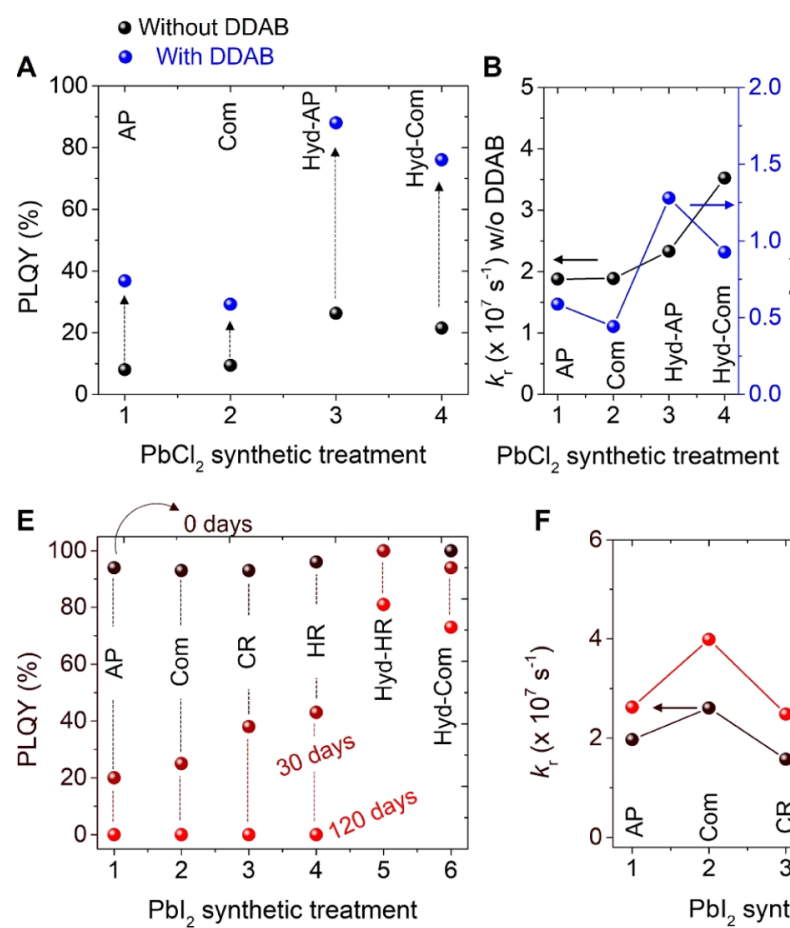

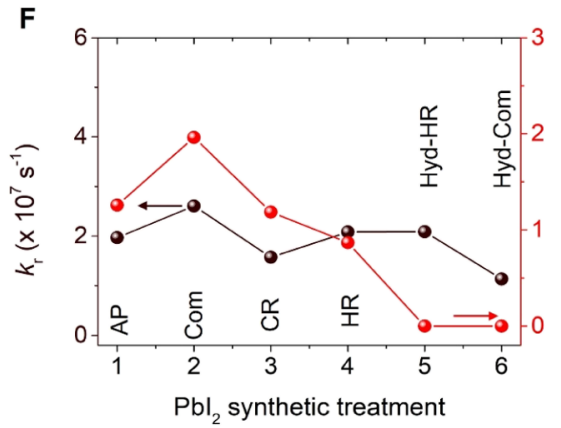

C 5

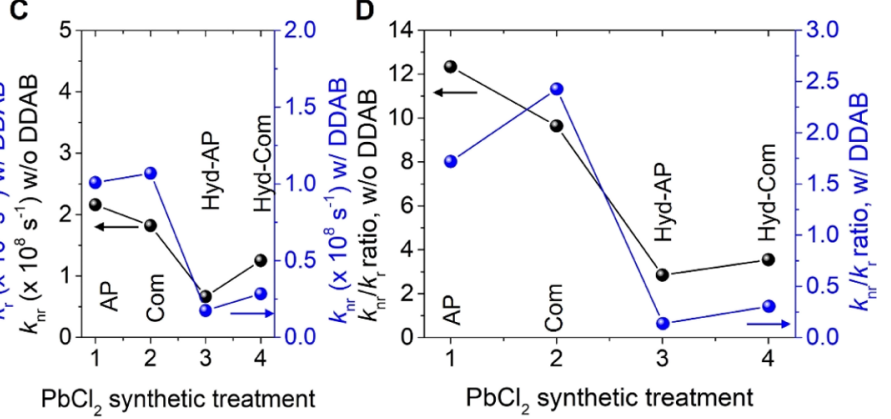

G

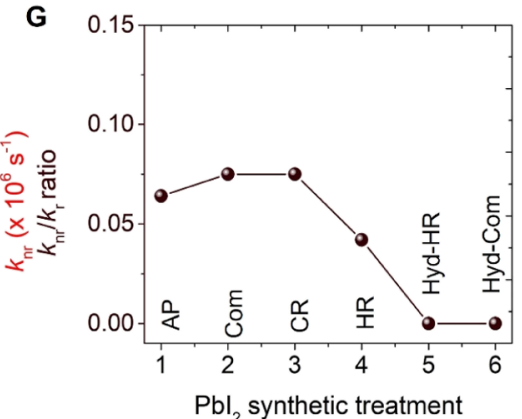

Figure 3. Behavior of $(\mathrm{A}, \mathrm{E})$ PLQY, $(\mathrm{B}, \mathrm{C}, \mathrm{F})$ radiative $\left(k_{\mathrm{r}}\right)$ and nonradiative recombination $\left(k_{\mathrm{nr}}\right)$ decay constants, and their corresponding $k_{\mathrm{r}} / k_{\mathrm{nr}}$ ratio for (A-D) MHP PNCs in the absence (black dots) and presence of DDAB (blue dots) and (E-G) CsPI PNCs synthesized with different crystallized and purified $\mathrm{PbCl}_{2}$ and $\mathrm{PbI}_{2}$ precursors, respectively.

band structure to conduct photocatalytic reactions, as we will show later.

The diverse recrystallization/purification processes of $\mathrm{PbX}_{2}$ also impact on the surface environment and chemical speciation of the $\mathrm{CsPbCl}_{3-x} \mathrm{Br}_{x}$ and $\mathrm{CsPbI}_{3}$ PNCs, as it was analyzed by X-ray photoelectron spectroscopy (XPS). Through survey spectra, the coexistence of $\mathrm{C}, \mathrm{N}, \mathrm{O}, \mathrm{Cs}$, and $\mathrm{Pb} ; \mathrm{Cl}$ and $\mathrm{Br}$ into MHPs, and I atoms in CsPI was identified (Figure $\mathrm{S} 8 \mathrm{~A}, \mathrm{~B})$. The chemical composition of the materials is summarized in Tables S5 and S6. Figure 2A, $\mathrm{A}^{\prime}$ depicts the high-resolution (HR) XPS spectra of the Cs $3 \mathrm{~d}$ spectra of MHPs and CsPI samples, showing two characteristic doublets $\sim 724 / 738 \mathrm{eV}$. These signals correspond to the Cs $3 \mathrm{~d}_{5 / 2}$ and Cs $3 \mathrm{~d}_{3 / 2}$ core levels, respectively, ascribed to the presence of $\mathrm{Cs}^{+}$species in the $\mathrm{CsPbX}_{3}$ structure. ${ }^{60}$ Furthermore, it also evidenced that the doublets are displaced to lower binding energies (BEs) in both kinds of materials. In the case of MHPs, this trend is associated to the increase of bromine in the PNCs as the Hyd purification is conducted, corroborating that $\mathrm{Br}^{-}$ domains compensate the halide positions during PNC formation (see Table S5). In the case of CsPI materials, the $\mathrm{BE}$ shift of the Cs $3 \mathrm{~d}$ peaks is ascribed to the presence of more iodide species coming from a more purified $\mathrm{PbI}_{2}$.

Although AP-, CR-, and HR-CsPI also feature an excess of iodide compared to the I-deficient Com-CsPI (deducted from a $\mathrm{I} / \mathrm{Pb}$ ratio higher than 3 , Table $\mathrm{S6}$ ), these materials show some $\mathrm{Cs}^{+}$deficiency, suggesting an alteration in the stoichiometry of $\mathrm{CsPbI}_{3}$ PNCs. This deficiency is also exhibited in the MHPs (Table S5), which is reduced by reaching the suitable $\mathrm{Pb} /(\mathrm{Cl}+\mathrm{Br})$ ratio of $\sim 1: 3$ for the $\mathrm{Hyd}$ AP-MHPs sample. The presence of $\mathrm{Cs}^{+}$defects in MHPs and CsPI materials is associated with the reactions taking place during their synthesis, where a defective $\mathrm{PbX}_{2}$ precursor is critical to impact the stoichiometry and stabilization of the final product (Supporting Information, page 10).

Figure $2 \mathrm{~B}$ shows the HRs-XPS $\mathrm{Cl} 2 \mathrm{p}$ and $\mathrm{Br} 3 \mathrm{~d}$ spectra of the corresponding MHPs obtained by using different $\mathrm{PbCl}_{2}$ precursors with and without Hyd purification. Typical doublets $2 \mathrm{p}_{3 / 2}$ and $2 \mathrm{p}_{1 / 2}$ core levels were observed in the $\mathrm{Cl} 2 \mathrm{p}$ spectra, associated with $\mathrm{Pb}-\mathrm{Cl}$ bonds $(\sim 197.6 / 199 \mathrm{eV}) .{ }^{50}$ Meanwhile, the characteristic $3 \mathrm{~d}_{5 / 2}$ and $3 \mathrm{~d}_{3 / 2}$ core levels $\sim 68 / 69 \mathrm{eV}$ appeared in the $\mathrm{Br} 3 \mathrm{~d}$ spectra, ascribed to $\mathrm{Pb}-\mathrm{Br}$ species. ${ }^{50,61}$ The coexistence of $\mathrm{Pb}-\mathrm{Cl}$ and $\mathrm{Pb}-\mathrm{Br}$ bonds confirms the formation of the $\mathrm{CsPbCl}_{3-x} \mathrm{Br}_{x}$ mixed-halide structure. Furthermore, in both $\mathrm{Cl} 2 \mathrm{p}$ and $\mathrm{Br} 3 \mathrm{~d}$ spectra, a displacement of BEs to lower values for Hyd-AP- and Hyd-Com-MHPs takes place, compared to that for AP- and Com-MHPs, corroborating the substitution of $\mathrm{Cl}^{-}$domains by the $\mathrm{Br}^{-}$species into the perovskite lattice. This trend agrees well with the chemical composition shown in Table $\mathrm{S} 5$, where the $\mathrm{Cl} /(\mathrm{Cl}+\mathrm{Br})$ ratio is decreased for MHPs grown by using purified $\mathrm{PbCl}_{2}$. On the other hand, Figure 2 $\mathrm{B}^{\prime}$ shows the HRs-XPS I $3 \mathrm{~d}$ spectra of the CsPI samples synthesized by using recrystallized and purified $\mathrm{PbI}_{2}$. In all the materials, the corresponding spin-orbit splitting $3 \mathrm{~d}_{5 / 2}$ and $3 \mathrm{~d}_{3 / 2}$ signals are observed $\sim 618.3 / 630 \mathrm{eV}$, associated to the iodide species from the $\left[\mathrm{PbI}_{6}\right]$ octahedra making up the PNCs. ${ }^{61}$ In addition, no changes in the BEs of the I 3d doublets were evidenced, indicating that the nature of the treated $\mathrm{PbI}_{2}$ does not produce any secondary structures than the expected 3D. Nevertheless, the iodide content appears to be higher after Hyd purification as we can infer by the increase of the $\mathrm{I} / \mathrm{Pb}$ ratio displayed in Table S6. Hence, it is concluded that the Hyd treatment is vital for improving the crystallinity of $\mathrm{PbX}_{2}$ by filling halide defects into $\left[\mathrm{PbX}_{6}\right]$ units in the halide precursor. This triggers that more halide species participate in the formation of less-defective $\mathrm{CsPbX}_{3}$ PNCs and their stabilization through surface passivation. 
Figure $2 \mathrm{C}, \mathrm{C}^{\prime}$ shows the HRs-XPS $\mathrm{Pb} 4 \mathrm{f}$ spectra of the MHPs and CsPI materials, respectively, where representative $\mathrm{Pb} 4 \mathrm{f}_{7 / 2}$ and $\mathrm{Pb} 4 \mathrm{f}_{5 / 2}$ core levels were attained $\sim 138 / 143 \mathrm{eV}$ in both cases. These signals are associated to the presence of $\mathrm{Pb}^{2+}$ from the $\mathrm{CsPbCl}_{3-x} \mathrm{Br}_{x}$ and $\mathrm{CsPbI}_{3}$ PNC structures, respectively. ${ }^{50,60}$ Similar to the described elements above, the displacement of the $\mathrm{BEs}$ of the $\mathrm{Pb} 4 \mathrm{f}$ doublets in the case of MHPs corresponds to the $\mathrm{Br}^{-}$incorporation into the perovskite to produce more $\mathrm{Pb}-\mathrm{Br}$ bonds, while this shift observed in the CsPI samples is ascribed to a higher density of iodide species to produce more $\mathrm{Pb}-\mathrm{I}$ bonds into PNCs. Surprisingly, in all the MHPs and CsPI samples with some halide deficiency, we did not observe the presence of metallic lead as it has been reported in our previous works. ${ }^{5,61}$ This discrepancy can be related to the use of MeOAc as the antisolvent to wash the PNCs. This solvent removes some surface ligands and unreacted species after the material synthesis and passivates the halide vacancies to bind the undercoordinated $\mathrm{Pb}$ through the $\mathrm{COO}^{-}$anions, as reported by Zhang and coworkers. ${ }^{62}$ As seen in Tables S5 and S6, the oxygen-to-total halide ratio [defined as $\mathrm{O}_{\text {total }} /\left(\mathrm{X}+\mathrm{O}_{\text {total }}\right)$ ] is the lowest one for the Hyd-AP-MHPs and Hyd-HR-CsPI samples, also achieving a high $\mathrm{Cs}^{+}$content (Figure 2D,D'). This fact allows us to deduce that the density of structural defects compensated with the MeOAc decreases significantly by using Hyd-purified $\mathrm{PbI}_{2}$ with fixed $\left[\mathrm{PbX}_{6}\right]$ octahedra and suitable stoichiometry.

Given that the quality of the $\mathrm{PbX}_{2}$ exhibits a high impact on the density of surface defects of PNCs, it is evident that fixing the stoichiometry from $\mathrm{Pb}-\mathrm{X}$ octahedra in halide precursors leads to a final product with a lower deficiency of species such as $\mathrm{Cs}^{+}$and $\mathrm{X}^{-}$. Thus, by using different crystallization treatments and purification steps on $\mathrm{PbX}_{2}$ through defect engineering, it is possible to reduce the probability to obtain highly defective PNCs, improving their photophysical properties and stability. Under these premises, we studied the PLQY of MHPs and CsPI samples synthesized with different treated $\mathrm{PbCl}_{2}$ and $\mathrm{PbI}_{2}$ precursors, respectively. As seen in Figure 3A, the highest PLQY of $\sim 26 \%$ is achieved for Hyd-AP-MHPs, followed by the Hyd-Com-MHPs (21\%), compared to their nontreated counterparts. As mentioned above, the appearance of more $\mathrm{Pb}-\mathrm{Cl}$ bonds into $\mathrm{PbCl}_{2}$ after the $\mathrm{Hyd}$ process improves their stoichiometry, which would provide $\mathrm{Cl}^{-}$species to take part in the MHP growth. However, the high complexation affinity of $\mathrm{Pb}-\mathrm{Cl}$ makes difficult the dissolution of the halide precursor, indicating that more $\mathrm{Br}^{-}$species from $\mathrm{PbBr}_{2}$ fill the halide sites into the perovskite structure. Consequently, the density of deep states provided by the $\mathrm{Cl}$ vacancies is reduced, decreasing the nonradiative recombination sites. Further mechanistic insights into the recombination dynamics of the MHPs were obtained by time-resolved PL (TRPL) measurements (Figure S9A), collecting their corresponding average electron lifetimes, $\tau_{\text {avg, }}$ by fitting the PL decays through a triexponential equation, $y=y_{0}+A_{1} \mathrm{e}^{-x / \tau_{1}}+$ $A_{2} \mathrm{e}^{-x / \tau_{2}}+A_{3} \mathrm{e}^{-x / \tau_{3}}$. Each decay component was associated to the nonradiative recombination promoted by shallow defects $\left(\tau_{1}\right)$, radiative recombination $\left(\tau_{2}\right)$, and the presence of deep states $\left(\tau_{3}\right)$, respectively. ${ }^{50,63}$ According to Table S7, $\tau_{3}<\tau_{2}<\tau_{1}$ in MHP growth using $\mathrm{PbCl}_{2}$ in the absence of $\mathrm{Hyd}$ purification. This fact allows us to deduce that the carrier trapping through deep states is favored (high density of $\mathrm{Cl}^{-}$ vacancies). However, after $\mathrm{PbCl}_{2}$ purification, $\tau_{3}>\tau_{2}>\tau_{1}$, indicating that shallow states govern the nonradiative recombination pathway into MHPs (incorporation of $\mathrm{Br}^{-}$ species to compensate the $\mathrm{Cl}^{-}$deficiency).

Then, by purifying $\mathrm{PbCl}_{2}$, the longer is the $\tau_{\text {avg }}$ indicating that the carrier recombination is retarded (Table S7). ${ }^{64}$ In addition, through the PLQY and $\tau_{\mathrm{avg}}$ values, radiative and nonradiative recombination constants $\left(k_{\mathrm{r}}\right.$ and $k_{\mathrm{nr}}$, respectively) are determined, as indicated in Table S8. While Com-, AP-, and Hyd-AP-MHPs show a similar $k_{\mathrm{r}}$, Hyd-Com-MHPs present a higher value (Figure $3 \mathrm{~B}$ ). This can be ascribed to the $\mathrm{Cl} /(\mathrm{Cl}+\mathrm{Br})$ ratio of the corresponding materials (estimated from XPS), where the density of $\mathrm{Br}^{-}$domains exceeds that of the $\mathrm{Cl}^{-}$ones in Hyd-Com-MHPs. Nevertheless, since the $(\mathrm{Cl}+\mathrm{Br}) / \mathrm{Pb}$ ratio of this material is lower than that of Hyd-AP-MHPs, we infer that there is a higher density of halide vacancies to produce nonradiative recombination centers. We can corroborate this argument by observing $k_{\mathrm{nr}}$ (Figure 3C), where Hyd-Com-MHPs show the highest value. Conversely, the lowest $k_{\mathrm{nr}}$ and, thereby, the $k_{\mathrm{nr}} / k_{\mathrm{r}}$ ratio (Figure 3D) are achieved by Hyd-AP-MHPs, deducing that the nonradiative channel is hindered to increase the PLQY. ${ }^{5}$ Despite this enhancement, the PLQY is still low (less than $30 \%$ ), which means that there are enough halide vacancies to quench the radiative recombination channels and to harm the optical features of the MHPs. Consequently, by adding DDAB into the MHP colloidal solutions, their corresponding PLQY (up to $88 \%$ ) and $k_{\mathrm{r}}$ increased (Figure $3 \mathrm{~A}, \mathrm{~B}$ ), while $k_{\mathrm{nr}}$ and $k_{\mathrm{nr}} /$ $k_{\mathrm{r}}$ significantly reduced, as the case of Hyd-AP-MHPs (Figure $3 \mathrm{C}, \mathrm{D})$. Here, the trend of $\tau_{\text {avg }}$ in DDAB-MHPs was similar to that of the pristine ones, fitting their corresponding TRPL decays to a triexponential equation, as discussed above (Figure S9B and Table S8). At this stage, we can deduce that DDAB passivates the MHP surface by filling some deep states, mediating the radiative recombination pathway. To propose how DDAB passivates the MHPs, we achieved HRs-XPS Cl 2p/Br 3d (Figure S10 and Table S9) and UV-vis absorption spectra (Figure S11) in these materials in the presence of the ligand. A partial exfoliation of the PNC surface to replace/fill $\mathrm{Cs}^{+}$cations by $\mathrm{DDA}^{+}$ones was observed, while $\mathrm{Br}^{-}$anions compensate $\mathrm{Cl}^{-}$vacancies to reduce the fraction of deep states (Supporting Information, page 12).

In the case of the CsPI materials, the Com-AP- and recrystallized samples show a PLQY higher than 90\%, while Hyd-treated CsPI achieved a value of up to $100 \%$ (Figure 3E). This fact demonstrates the growth of high-quality $\mathrm{CsPbI}_{3}$ PNCs with suppressed nonradiative recombination channels by using our synthetic protocol, which has been published previously. ${ }^{45}$ Subsequent PLQY measurements were obtained during 4 months under ambient conditions and a relative humidity $(\mathrm{RH})$ of $50-60 \%$, where the PLQY of the Com-, AP-, and recrystallized CsPI decreases after being practically negligible after 1 month. Meanwhile, Hyd-HR- and Hyd-ComCsPI preserve their optical feature after 4 months, reaching PLQYs of $\sim 81$ and $73 \%$, respectively. We associate this discrepancy in stability to the presence of the high oxygen content to compensate the halide vacancies and the generation of high $\mathrm{Cs}^{+}$deficiency from the PNC surface. Clearly, AP-, Com- CR-, and HR-CsPI show both an excess of the adsorbed oxygen to instigate the self-degradation of the PNCs and the presence of $\mathrm{Cs}^{+}$defects to induce transformation into the $\alpha$-to$\beta$-phase transformation through octahedral distortion. Then, although the Hyd-treated CsPI does not exhibit $\mathrm{Cs}^{+}$deficiency as we noted by XPS (Table S6), Hyd-Com-CsPI contains a higher fraction oxygen compared to that of Hyd-HR-CsPI. 


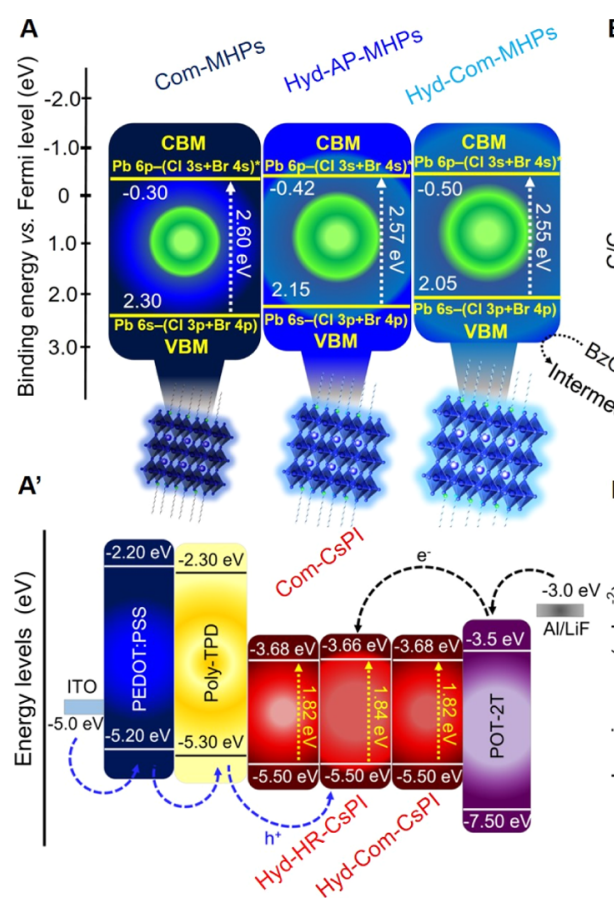

B

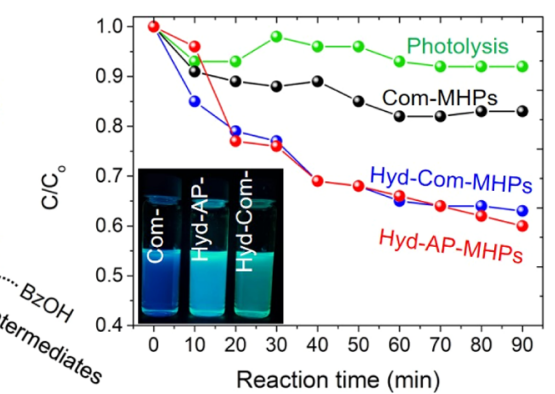

B'

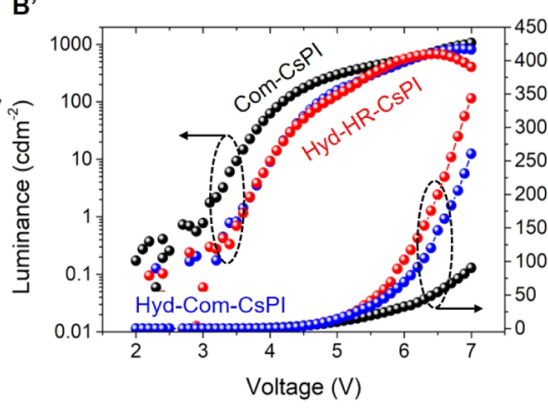

C

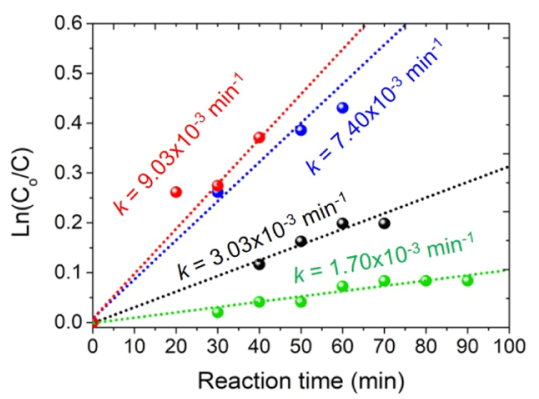

C'

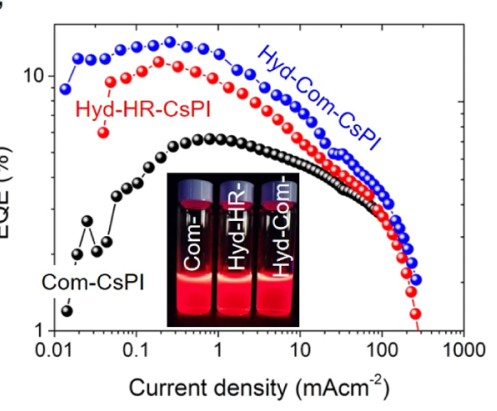

Figure 4. (A) Band structure (vs Fermi level) of DDAB-treated MHPs obtained from normalized XPS VB spectra through the extrapolation method. (B) Photodegradation of benzyl alcohol $(\mathrm{BzOH}, 1.5 \mathrm{mM})$ vs time and the $(\mathrm{C})$ corresponding kinetic rate curves obtained in the absence (green line) and presence of DDAB-treated MHPs: Com-MHPs (black line), Hyd-AP-MHPs (red line), and Hyd-Com-MHPs (blue line). (A') Relative energy band positions of a $\mathrm{CsPbI}_{3}-\mathrm{LED}$ configuration. Performance characterization of devices: $\left(\mathrm{B}^{\prime}\right) J-V-L$ curves (current density, right side and luminance, left side) and $\left(\mathrm{C}^{\prime}\right)$ maximum $\mathrm{EQE}$ obtained from $\mathrm{CsPbI}_{3}$-LED fabricated from CsPI samples: Com-CsPI (black dots), HydHR-CsPI (red dots), and Hyd-Com-CsPI (blue dots). Insets of $\left(\mathrm{B}, \mathrm{C}^{\prime}\right)$ depict the PNC solutions used during photocatalytic tests and device fabrication, respectively.

This fact can be the reason to generate a faster decrease in the PLQY. Similar to MHPs, TRPL measurements were obtained to study the recombination kinetics of CsPI (Figure S12). TRPL decays of all CsPI materials were fitted by a biexponential function to calculate $\tau_{\mathrm{avg}} k_{\mathrm{r}}, k_{\mathrm{nr}}$, and $k_{\mathrm{nr}} / k_{\mathrm{r}}$ parameters (Table S10). Although the PL decays of Hydtreated CsPI with $100 \%$ PLQY are close to show a monoexponential behavior, a biexponential fitting describes their PL dynamics better. The fact that the PL decay profile of Hyd-treated CsPI does not exhibit a monoexponential behavior has been related to the trapping-detrapping process with shallow defects in the perovskite conduction band (CB), as reported in our previous works. ${ }^{5,65}$

By comparing the recrystallization and purification processes, CsPI samples show a similar $k_{\mathrm{r}}$, while Hyd-treated samples exhibit a suppressed $k_{\mathrm{nr}}$ (Figure $3 \mathrm{~F}$ ) and $k_{\mathrm{nr}} / k_{\mathrm{r}}$ ratio (Figure $3 \mathrm{G}$ ). This fact corroborates that Hyd purification is the best treatment to enhance the crystallinity of $\mathrm{PbI}_{2}$, associated to the reduction of iodide-mediated defects (electron traps) and support the radiative channel. Accordingly, we conclude that Hyd-treated $\mathrm{PbX}_{2}$ facilitates the synthesis of less-defective and stable $\mathrm{CsPbX}_{3}$ PNCs with better surface stoichiometry, suppressed nonradiative recombination traps, and improved photophysical properties that eventually will impact the devices and systems prepared with them suitable among other for optoelectronics and solar-driven chemistry. We have highlighted this fact by preparing LEDs and carrying out photocatalyst experiments comparing the performance of these systems fabricated with both PNCs synthesized with commercial and with Hyd-treated $\mathrm{PbX}_{2}$ precursors.

We carried out the photocatalytic (PC) oxidation of benzyl alcohol $(\mathrm{BzOH})$ as a model molecule under ambient air by using DDAB-modified Com-, Hyd-AP-, and Hyd-Com-MHP colloidal solutions. Prior to conducting the photooxidation of the organic molecule, we have established the band structures of these materials by determining their corresponding valence band (VB)- and CB-relative positions (Figure 4A). This was performed to understand the relationship between the electronic structure of MHPs in their PC properties. ${ }^{61}$ Through normalized XPS VB spectra, we estimated the ascribed VB energy $\left(E_{\mathrm{VB}}\right)$ of MHPs by using the extrapolation method (Figure S13). We further calculated the CB energy $\left(E_{\mathrm{CB}}\right)$ through the equation $E_{\mathrm{VB}}=E_{\mathrm{CB}}+E_{\mathrm{g}}$. Here, $E_{\mathrm{g}}$ of Com-, Hyd-AP-, and Hyd-Com-MHPs after DDAB addition was estimated to be 2.60, 2.57, and $2.55 \mathrm{eV}$ from PL spectra. Although the MHPs contain the same amount of DDAB, $E_{\mathrm{VB}}$ was displaced to more negative energy values in the following order: Hyd-Com- > Hyd-AP- > Com-MHPs. This trend suggests the increase of the $\mathrm{Br}^{-}$content to fill the halide positions into MHPs likely leading to a lower oxidizing power for the photocatalysts. However, the band gap narrowing improves the light harvesting to generate more photocarriers. The balance between the band gap and $E_{\mathrm{VB}}$ is pivotal to favor the PC activity of the materials.

After studying the band structure of the blue-emitting MHPs, we performed the PC oxidation of $\mathrm{BzOH}$, which was monitored through the characteristic UV-vis absorption spectrum from the organic molecule, in the absence and presence of MHPs under continuous UV-vis light illumination for $90 \mathrm{~min}$ (Figure S14A-D). The change in the absorbance of $\mathrm{BzOH}$ described as $\mathrm{C} / \mathrm{C}_{0}$ was measured every $10 \mathrm{~min}$ (Figure $4 \mathrm{~B}$ ), being $C$, the concentration as a function of time and $C_{0}$, the initial concentration. The respective pseudo-first-order rate constants $(k)$ were obtained from the photo-oxidation curves 
by using the equation $\ln \left(C_{0} / C\right)=k t$, where $t$ is the reaction time (Figure 4C). MHP colloidal solutions are shown in the inset of Figure 4B. In the absence of the photocatalyst, photolysis provides the lowest decrease of the $C / C_{0}$ ratio $(\sim 8 \%)$, in addition to the subsequent appearance of new signals at lower wavelengths. We have corroborated the photochemical oxidation of $\mathrm{BzOH}$ to benzaldehyde (BzCHO) by achieving the typical UV-vis spectrum of this organic molecule. Then, in the presence of the photocatalysts, the highest PC performance and $k$ was obtained for Hyd-APMHPs, with a maximum photodegradation efficiency of $\sim 40 \%$, followed by Hyd-Com-MHPs (37\%) and Com-MHPs (17\%). As such, we conclude that Hyd-AP-MHPs reached a suitable balance between the band gap and highly oxidizing VB-relative position, suggesting that $\mathrm{BzOH}$ molecules can be consumed faster by photogenerated holes in the $\mathrm{PNC} /$ solution interface. Interestingly, the emergence of $\mathrm{BzCHO}$ was not confirmed during the reaction, indicating that an alternative oxidation mechanism takes place. By tracking the PL spectra of MHPs in the presence of $\mathrm{BzOH}$ for 60 min (Figure S15), we observed a redshift in the emission peak position for the three different materials, which is a notorious indication that a ligand exchange between $\mathrm{BzOH}$ molecules and OA/OLA is generated. The binding of $\mathrm{BzOH}$ to the PNC surface could be the first step to promote the selective formation of different species, for instance, benzoic acid or benzyl benzoate, which would be attractive to analyze in future works. Hence, we can conclude that Hyd-treated MHPs can photocatalyze organic reactions with enhanced efficiency by establishing an adequate equilibrium between their optical properties and oxidizing power. $^{61,66}$

In the case of red-emitting PNCs, Com-, Hyd-HR-, and Hyd-Com-CsPI colloidal solutions were used to fabricate LEDs through the architecture ITO/PEDOT/PSS/poly-TPD/ $\mathrm{CsPb}_{3} / \mathrm{PO}-\mathrm{T} 2 \mathrm{~T} / \mathrm{LiF} / \mathrm{Al}$ (Figure $4 \mathrm{~A}^{\prime}$ ). The relative energy band positions of the LED configuration have previously been reported. ${ }^{4567}$ Images of CsPI colloidal solutions used here are shown in the inset of Figure $4 C^{\prime}$. These configurations ensure the suitable injection of carriers into the PNC layer. ${ }^{67}$ Then, in order to avoid the effect of external factors on device fabrication such as PNC concentration, thickness of active, electron, and hole transport layers, and so forth, we prepared different batches of LED devices using the corresponding MHPs and CsPI PNCs for the optimization process. For $\mathrm{CsPb}_{3}$-based LEDs, $J-V-L$ characteristics and EQE (Figure $\left.4 \mathrm{~B}^{\prime}, \mathrm{C}^{\prime}\right)$ illustrate the performance of Com-CsPI $(L=1065 \mathrm{~cd}$ $\mathrm{m}^{-2}, J=93 \mathrm{~mA} \mathrm{~cm}{ }^{-2}$, and EQE $\left.=5.6 \%\right)$, Hyd-HR-CsPI $(L=$ $679 \mathrm{~cd} \mathrm{~m}^{-2}, J=344 \mathrm{~mA} \mathrm{~cm}{ }^{-2}$, and EQE $\left.=11.4 \%\right)$, and HydCom-CsPI $\left(L=832 \mathrm{~cd} \mathrm{~m}^{-2}, J=260 \mathrm{~mA} \mathrm{~cm}{ }^{-2}\right.$, and EQE $=$ $13.6 \%)$. All the systems presented a turn-on voltage of around $5 \mathrm{~V}$ and also a roll-of effect at currents of $\sim 100 \mathrm{~mA} \cdot \mathrm{cm}^{-2}$ which is near to the operation features of $\mathrm{CsPbI}_{3} \mathrm{LED}$ previously shown. ${ }^{45}$ Attending to the high oxygen content found in Com-CsPI coming from MeOAc to compensate the halide vacancies and restrain the presence of metallic lead, we suggest that this emitting layer contains enough short carbonchain acetate anions to facilitate the carrier injection into the device. Nevertheless, the nonsuitable stoichiometry coming from this material allows us to deduce that the carriers can be trapped by nonradiative recombination sites. This is reported to be a main reason for the current leakage and produce an unbalanced charge injection.
Then, although both Hyd-treated PNCs display enhanced PL properties, we infer that the presence of a higher content of $\mathrm{MeOAc}$ species and an adequate stoichiometry established in the Hyd-Com-CsPI provides a better carrier injection transport into the active layer, compared to Hyd-HR-CsPI. In this way, a slight increase of the EQE can be reached. This fact can also be corroborated through electroluminescence measurements (Figure S16A-C) where the Hyd-Com-CsPI featured the highest emission intensity. Nevertheless, the Hydtreated CsPI devices exhibit improved radiative carrier recombination, leading to an increased performance of the red-emitting LEDs. Hence, we demonstrate that the crystallization and purification of $\mathrm{PbX}_{2}$ precursors open the door for the defect engineering to synthesize less-defective PNCs, with enhanced photophysical and electronic properties, to be chosen as a potential option for the fabrication of highly efficient optoelectronic devices.

\section{CONCLUSIONS}

By studying diverse strategies to enhance the crystallinity and quality of $\mathrm{PbCl}_{2}$ and $\mathrm{PbI}_{2}$ precursors, we establish the synthesis of $\mathrm{CsPbCl}_{3-x} \mathrm{Br}_{x}$ and $\mathrm{CsPbI}_{3}$ PNCs with reduced structural defects that produce improved photophysical properties and stability. We elucidated that the $\mathrm{Hyd}$ purification of $\mathrm{PbCl}_{2}$ promotes the filling of $\mathrm{Cl}$ vacancies existing in the halide precursor structure, providing more $\mathrm{Pb}-\mathrm{Cl}$ bonds. However, the high complexation affinity of $\mathrm{Pb}-\mathrm{Cl}$ restrains the dissolution of purified $\mathrm{PbCl}_{2}$, indicating that more $\mathrm{Br}^{-}$species from $\mathrm{PbBr}_{2}$ occupy the halide domains in the perovskite structure. Consequently, the density of deep states provided by the $\mathrm{Cl}$ vacancies is reduced, decreasing the nonradiative carrier traps. In this way, the ligand passivation through the addition of DDAB is maximized, achieving a high PLQY of around $88 \%$. In the case of red-emitting PNCs, the HR process followed by the Hyd treatment compensates the halide deficiency presented in $\mathrm{PbI}_{2}$, indicating that more $\mathrm{I}^{-}$species can participate in the $\mathrm{CsPb}_{3}$ perovskite growth. A suitable surface stoichiometry is obtained, hindering the octahedra tilting and stabilizing the photoactive black cubic $\alpha$-phase. Thus, we were able to reach a PLQY of up to $100 \%$, suppressing the nonradiative recombination pathways and facilitating the radiative recombination dynamics. Under this consideration, PLQY of the samples only displayed a decrease of $19 \%$ after 4 months under ambient air and $\mathrm{RH} \sim 50-60 \%$, indication of their long-term stability, confirming that decreased defect density not just increases performance but stability. Ultimately, the preparation of less-defective PNCs enhances the performance of the systems and devices prepared with these PNCs. Hyd-treated $\mathrm{CsPbCl}_{3-x} \mathrm{Br}_{x}$ PNCs were used as photocatalysts to photo-oxidize $\mathrm{BzOH}$, yielding $40 \%$ during the reaction, doubling the performance of PNCs synthesized with commercial precursors. On the other hand, LEDs prepared with Hyd-treated $\mathrm{CsPbI}_{3}$ PNCs also double the EQE of LEDs fabricated with commercial precursors, achieving a maximum EQE of $13.6 \%$. Therefore, we prove that the purification of $\mathrm{PbX}_{2}$ precursors prior to the PNC synthesis is a valuable approach to guarantee the growth of a high-quality and stable material, with efficient optical performance, which are attractive features for the development of improved solardriven processes and efficient LED technologies, and this strategy could be successfully extrapolated to other optoelectronic devices in order to increase their performance and longterm stability. 


\section{EXPERIMENTAL SECTION}

4.1. Purification of $\mathrm{PbX}_{2}$ Precursors. 4.1.1. $\mathrm{Pbl}_{2}$ and Recrystallization. The synthesis and purification of $\mathrm{PbI}_{2}$ were carried out following the "Golden Rain" method, ${ }^{49}$ provided by the Royal Society of Chemistry with minor modifications, which referred to our previous report. ${ }^{68}$ In brief, $3.793 \mathrm{~g}$ of $\mathrm{Pb}\left(\mathrm{CH}_{3} \mathrm{COO}\right)_{2}$ and $5.29 \mathrm{~g}$ of $\mathrm{KI}$ were dissolved in each 2 of $1 \mathrm{~L}$ distilled water bottles. $3 \mathrm{~mL}$ of $4 \mathrm{M}$ $\mathrm{HCl}$ was added to the lead acetate solution to prevent hydrolysis. Next, the two aqueous solution bottles were gradually mixed. During the mixing process, bright yellow lead iodide precipitations could be observed immediately. When the precipitation could be observed, the solution was heated until the precipitate dissolves in the solution. The heated solution was cooled to room temperature. The cooling process would take around $2 \mathrm{~h}$. About $2 \mathrm{~h}$ later, recrystallized $\mathrm{PbI}_{2}$ was formed. Furthermore, the $\mathrm{PbI}_{2}$ solution was placed in the refrigerator within $3 \mathrm{~h}$ to obtain $\mathrm{PbI}_{2}$ from the solution as much as possible. The recrystallized $\mathrm{PbI}_{2}$ was successively filtered to isolate $\mathrm{PbI}_{2}$. The filtered $\mathrm{PbI}_{2}$ was dried overnight in a vacuum oven.

4.1.2. $\mathrm{PbCl}_{2}$ and Recrystallization. $2.672 \mathrm{~g}$ of $\mathrm{PbCO}_{3}$ was dissolved in $1 \mathrm{~mL}$ of distilled water. Also, $10 \mathrm{~mL}$ of $4 \mathrm{M} \mathrm{HCl}$ was added to the lead carbonate solution. When $\mathrm{HCl}$ was added, the reaction in between lead carbonate and $\mathrm{HCl}$ occurred in the solutions and the bubbles of $\mathrm{CO}_{2}$ were generated. When the bubbling of $\mathrm{CO}_{2}$ was done, lead chloride could be observed with precipitation.

4.1.3. Hydrothermal Purification. Hydrothermal purification was carried out after the drying process. $0.8 \mathrm{~g}$ of $\mathrm{PbI}_{2}\left(3.2 \mathrm{~g}\right.$ of $\left.\mathrm{PbCl}_{2}\right)$ and $120 \mathrm{~mL}$ of distilled water were placed in a $150 \mathrm{~mL}$ Teflon-lined hydrothermal autoclave. The autoclave was maintained at $200{ }^{\circ} \mathrm{C}$ for $6 \mathrm{~h}$ and then cooled to room temperature for $18 \mathrm{~h}$. The crystallized $\mathrm{PbX}_{2}$ was filtered and dried overnight in a vacuum oven.

The corresponding precipitation reaction schemes of $\mathrm{PbX}_{2}(\mathrm{X}=\mathrm{Cl}$ and I) are shown in eqs 1 and 2, respectively, as follows

$$
\begin{aligned}
& \mathrm{Pb}\left(\mathrm{CH}_{3} \mathrm{COO}\right)_{2(\mathrm{aq})}+2 \mathrm{KI}_{(\mathrm{aq})} \rightarrow \mathrm{PbI}_{2(\mathrm{~s})}+2 \mathrm{CH}_{3} \mathrm{COOK}_{(\mathrm{aq})} \\
& \mathrm{Pb}\left(\mathrm{CH}_{3} \mathrm{COO}\right)_{2(\mathrm{~s})}+2 \mathrm{HCl}_{(\mathrm{aq})} \rightarrow \mathrm{PbCl}_{2(\mathrm{~s})}+2 \mathrm{CH}_{3} \mathrm{COOH}_{(\mathrm{aq})}
\end{aligned}
$$

Furthermore, $\mathrm{PbX}_{2}$ materials were placed in deionized (DI) water in a Teflon-lined hydrothermal autoclave, and during the hydrothermal process with increasing temperature to $200{ }^{\circ} \mathrm{C}$, insoluble $\mathrm{PbX}_{2}$ with impurities at $25{ }^{\circ} \mathrm{C}$ starts to dissolve and crystallized/ purified materials were able to be obtained.. Note that $\mathrm{PbCO}_{3}$ was also obtained as a byproduct during the precipitation process. This is because the reaction occurs in aqueous solution under ambient air conditions, where $\mathrm{CO}_{2}$ in air could dissolve in the solution and induce the following reaction, as a competitive reaction with reaction 1

$$
\begin{aligned}
& \mathrm{Pb}\left(\mathrm{CH}_{3} \mathrm{COO}\right)_{2(\mathrm{aq})}+2 \mathrm{H}_{2} \mathrm{CO}_{3(\mathrm{aq})} \\
& \rightarrow \mathrm{PbCO}_{3(\mathrm{~s})}+2 \mathrm{CH}_{3} \mathrm{COOH}_{(\mathrm{aq})}
\end{aligned}
$$

To reduce the formation of byproducts, $\mathrm{HCl}$ was added since (i) it increases the yield by decreasing the $\mathrm{pH}<5^{69}$ and (ii) it prevents lead carbonate formation. ${ }^{19}$ To improve the quality of $\mathrm{PbX}_{2}$, the recrystallization/hydrothermal process facilitates the thermodynamic decomposition of $\mathrm{PbCO}_{3}$ by producing $\mathrm{CO}_{2}$ gas with lower solubility at a higher temperature, so the byproduct $\mathrm{PbCO}_{3}$ (reverse reaction in eq 3) could be removed after the recrystallization/hydrothermal process.

4.2. Synthesis of $\mathrm{CsPbCl}_{3-x} \mathrm{Br}_{x}$ and $\mathrm{CsPbl}_{3} \mathrm{PNCs}$ by Hot Injection. $\mathrm{CsPbCl}_{3-x} \mathrm{Br}_{x}$ mixed halide (MHPs) and $\mathrm{CsPbI}_{3}$ (CsPI) PNCs were obtained by a hot-injection synthetic protocol through stoichiometrically mixing both the Cs-oleate and $\mathrm{PbCl}_{2} / \mathrm{PbBr}_{2}$ and $\mathrm{PbI}_{2}$ solutions with some modifications. ${ }^{61}$ For preparing the Cs-oleate solution, $0.61 \mathrm{~g}$ of $\mathrm{Cs}_{2} \mathrm{CO}_{3}$ (202126, 99.9\%, Sigma-Aldrich) and 2.0 $\mathrm{mL}$ of oleic acid (OA, 364525, 90\%, Sigma-Aldrich) were mixed in 30 $\mathrm{mL}$ of 1-octadecene (1-ODE, O806, 90\%, Sigma-Aldrich) into a 50 $\mathrm{mL}$ three-neck flask under vacuum for $30 \mathrm{~min}$ at $80{ }^{\circ} \mathrm{C}$. Then, the temperature was increased to $120^{\circ} \mathrm{C}$ and kept under vacuum for 30 min. By using a $\mathrm{N}_{2}$ purge, the mixture was heated at $150{ }^{\circ} \mathrm{C}$, dissolving $\mathrm{Cs}_{2} \mathrm{CO}_{3}$ completely. In order to prevent the Cs-oleate precipitation to produce $\mathrm{Cs}_{2} \mathrm{O}$, the resultant transparent solution was kept at $120^{\circ} \mathrm{C}$ under vacuum.

For synthesizing MHPs, $0.15 \mathrm{~g}$ of crystallized/purified $\mathrm{PbCl}_{2}$ [commercial (Com) ABCR; AB202087, 99.999\%], as-prepared (AP), commercial and AP + hydrothermal process (Hyd-Com, Hyd-AP, respectively), and $0.20 \mathrm{~g}$ of $\mathrm{PbBr}_{2}$ (ABCR; AB202085, $99.998 \%$ ) were mixed with $25 \mathrm{~mL}$ of ODE into a $100 \mathrm{~mL}$ three-neck flask. In the case of CsPI, $0.50 \mathrm{~g}$ of crystallized/purified $\mathrm{PbI}_{2}$ (Com ABCR; AB111058, 99.999\%, Com TCI; L0279, 99.99\%, AP), coldcrystallized (CR), hot-crystallized, commercial, and HR + hydrothermal process (Hyd-Com- and Hyd-HR-, respectively) were mixed in a three-neck flask, with the same volume of 1-ODE.

The corresponding $\mathrm{PbX}_{2}$ mixtures were degasified at $120^{\circ} \mathrm{C}$ under vigorous stirring for $1 \mathrm{~h}$. Then, $2.5 \mathrm{~mL}$ of each preheated $\mathrm{OA}$ and oleylamine (HT-OA100, 98\%, Sigma-Aldrich) and $2 \mathrm{~mL}$ of trioctylphosphine (718165, 97\%, Sigma-Aldrich) for supporting the $\mathrm{PbCl}_{2} / \mathrm{PbBr}_{2}$ dissolution were added to the flask. Under a $\mathrm{N}_{2}$ atmosphere, the temperature of $\mathrm{PbCl}_{2} / \mathrm{PbBr}_{2}$ and $\mathrm{PbI}_{2}$ mixtures quickly increased to reach 170 and $190{ }^{\circ} \mathrm{C}$, respectively. Simultaneously, $2 \mathrm{~mL}$ of preheated Cs-oleate was rapidly injected, obtaining white MHPs and red CsPI precipitates in the colloidal solution. The flask was added into an ice bath for $5 \mathrm{~s}$ to quench the reaction mixture. For the isolating process, the dispersed PNCs were immediately centrifuged at 5000 for $5 \mathrm{~min}$ with methyl acetate (MeOAc, 296996, 99.5\%, Sigma-Aldrich) (all final QDs were liquorwashed with $60 \mathrm{~mL}$ of $\mathrm{MeOAc}$ ). PNC pellets were separated from the supernatant and redispersed with hexane (CHROMASOLV, 34859, $99.7 \%$, Honeywell) to concentrate at a desired value for further analysis $\left(50 \mathrm{mg} \mathrm{mL}^{-1}\right)$ and stored in the dark at $4{ }^{\circ} \mathrm{C}$ for at least $24 \mathrm{~h}$ to precipitate excess $\mathrm{Pb}$-oleate. The PNC solution was decanted and centrifuged again at $6500 \mathrm{rpm}$ for $5 \mathrm{~min}$ before use. Here, hexane was dried, and the final product was dissolved in $n$-octane (A13181, Alfa Aesar) at a concentration of $\sim 30 \mathrm{mg} \mathrm{mL}^{-1}$.

4.3. Characterization of Morphology, Structure, Optical Properties, and Chemical Environment of the $\mathrm{CsPbCl}{ }_{3-x} \mathrm{Br}_{x}$ and $\mathrm{CsPbl}_{3}$ PNCs. The morphology of the PNCs was evidenced by achieving HR TEM images by using a field-emission tunneling electron microscope (Hitachi HF-3300), with an applied bias of 300 $\mathrm{kV}$, and the crystalline structure for the PNCs with additional SAED patterns. The average particle size of PNCs was obtained from the TEM images with ImageJ software. XRD profiles of the $\mathrm{PbX}_{2}$ precursors and PNCs were obtained by using a X-ray diffractometer, PANalytical X'Pert PRO with the following factors: $2 \theta$ range of 5$80^{\circ}\left(0.02^{\circ} /\right.$ step and $\left.1.2 \mathrm{~s} / \mathrm{step}\right)$ using a $\mathrm{Cu} \mathrm{K} \alpha$ radiation source $(\lambda=$ $1.54056 \AA)$. UV-vis absorption spectra of PNC solutions were acquired by using a UV-vis absorption spectrophotometer (Varian, Cary 300). The wavelength range for the measurements was $400-850$ $\mathrm{nm}$. Steady-state and TRPL measurements were conducted using a PL spectrophotometer (Fluorolog 3-11, Horiba). An excitation wavelength of $420 \mathrm{~nm}$ was used to perform the steady-state PL. The concentration of the samples was fixed to $2 \mathrm{mg} \mathrm{mL}^{-1}$ in hexane using a quartz cuvette of $10 \times 10 \mathrm{~mm}$. TRPL measurements were performed at $405 \mathrm{~nm}$ pulsed laser (NanoLED-405L, $<100 \mathrm{ps}$ of pulse width, $1 \mathrm{MHz}$ frequency). The absolute PLQY of the MHP and CsPI solutions was estimated through a Hamamatsu PLQY Absolute QY Measurement System C9920-02, equipped with an integrating sphere, at an excitation wavelength of $400 \mathrm{~nm}$. Here, absorbance was adjusted in an interval range around $0.5-0.7$ to conduct the measurements, being these values suitable to achieve the maximum PLQY in the samples. Surface chemical composition and electronic state of PQDs were determined by XPS (ESCA-2R, Scienta-Omicron). Spectra were recorded using monochromatic $\mathrm{Al} \mathrm{K} \alpha=1486.6 \mathrm{eV}$. The following sequence of spectra were recorded: survey spectra, $\mathrm{C} 1 \mathrm{~s}, \mathrm{~Pb} 4 \mathrm{f}, \mathrm{I} 3 \mathrm{~d}$, $\mathrm{Cl} 2 \mathrm{p} \mathrm{Br} \mathrm{3d}, \mathrm{O} 1 \mathrm{~s}, \mathrm{~N} 1 \mathrm{~s}$, and $\mathrm{C} 1 \mathrm{~s}$ again to verify the stability of the charge as the function of time. The survey and HR spectra were recorded at a pass energy of 150 and $20 \mathrm{eV}$, respectively. The $\mathrm{BE}$ scale was referenced to adventitious carbon $(284.8 \mathrm{eV})$. CasaXPS processing software (Casa Software Ltd) was used to analyze the 
data, and the quantitative analysis was made using sensitivity factors provided by the manufacturer.

4.4. Photocatalytic Benzyl Alcohol (BzOH) Photodegradation. The photo-oxidation of $\mathrm{BzOH}$ was tracked through their characteristic maximum of absorbance $\sim 258 \mathrm{~nm}$ by using a Lambda 1050+ PerkinElmer UV/Vis/IR spectrophotometer. An organic solution containing $2.0 \mathrm{mg} \mathrm{mL}^{-1}$ PNCs and $15 \mathrm{mM} \mathrm{BzOH}$ in hexane was used for the photocatalytic measurements under ambient air. This solution ( $3 \mathrm{~mL}$ of total volume) was placed inside a quartz cuvette and irradiated at $100 \mathrm{~mW} \mathrm{~cm}^{-2}$ with an Oriel $300 \mathrm{~W}$ Xenon lamp. 50 $\mu \mathrm{L}$ of aliquots of this solution was extracted every $10 \mathrm{~min}$ to monitor the evolution of the absorbance at $258 \mathrm{~nm}$.

4.5. Fabrication of the $\mathrm{CsPbl}_{3}$-Based LEDs. In order to have an active area of $6 \mathrm{~mm}^{2}, 2.5 \times 2.5 \mathrm{~cm}^{2}$ ITO substrates $\left(10 \Omega / \mathrm{cm}^{2}\right)$ were partially covered with scotch tape. Then, the substrates were etched with zinc powder and $6 \mathrm{M} \mathrm{HCl}(37 \% \mathrm{HCl}$ was diluted with equal volume) one by one and wiped with tissue paper and rinsed with DI water. Then, scotch tape was removed and any remaining glue from tape was cleaned with paper and ethanol, and then, substrates were introduced in a soap solution and sonicated for $15 \mathrm{~min}$. Subsequently, ITO substrates were introduced in isopropanol and then in acetone, each one sonicated for another $15 \mathrm{~min}$ and dried with compressed air or nitrogen. After that, the substrates were introduced into a $\mathrm{UV}-\mathrm{O}_{3}$ cleaner for $20 \mathrm{~min}$ and the solution of PEDOT/PSS was spin-coated at $3000 \mathrm{rpm}$ for $30 \mathrm{~s}$ and annealed at $140{ }^{\circ} \mathrm{C}$ for $10 \mathrm{~min}$ in air to yield a thin layer $(20 \mathrm{~nm})$. Next, a poly-TPD layer was spin-coated $(20 \mathrm{mg} /$ $\mathrm{mL}$ in chlorobenzene) at different revolutions per minute (e.g., 4000 $\mathrm{rpm}$ ) for $30 \mathrm{~s}$ and subsequently annealed at $140{ }^{\circ} \mathrm{C}$ for $10 \mathrm{~min}$ in air. Solutions of CsPI $(30 \mathrm{mg} / \mathrm{mL})$ in $n$-octane were spin-coated at 3000 $\mathrm{rpm}$ for $30 \mathrm{~s}$. After that, $60 \mathrm{~nm}$ of POT-2T (for CsPI), $1 \mathrm{~nm}$ of LiF, and $100 \mathrm{~nm}$ of $\mathrm{Al}$ were thermally evaporated at rates of $0.2-0.3,0.05$, and $1.5-2 \AA / \mathrm{s}$, respectively. The LED characterization (EL spectra, $J-V-L$ curves, luminance, and $E Q E)$ was determined by using a Hamamatsu EQE measurement system (C9920-12) coupled with an integrating sphere connected to a PMA-12 photonic multichannel detector and a Keithley 2400 instrument as a current/voltage source meter.

\section{ASSOCIATED CONTENT}

\section{SI Supporting Information}

The Supporting Information is available free of charge at https://pubs.acs.org/doi/10.1021/acs.chemmater.1c02772.

XRD of lead halide precursors, histograms, SAED measurements, UV-vis, PL, and XPS spectra, PL decays and tables of the optical properties, surface chemical composition, carrier lifetime and PLQY of the $\mathrm{CsPbCl}{ }_{3-x} \mathrm{Br}_{x}$ and $\mathrm{CsPbI}_{3}$ PNCs colloidal solutions by using different crystallized and purified $\mathrm{PbCl}_{2}$ and $\mathrm{PbI}_{2}$, respectively, $\mathrm{UV}-$ vis and PL spectra of benzyl alcohol in the absence and presence of MHPs, and electroluminescence spectra of CsPI-based LEDs (PDF)

\section{AUTHOR INFORMATION}

\section{Corresponding Authors}

Seog Joon Yoon - Department of Chemistry, College of Natural Science, Yeungnam University, Gyeongsan, Gyeongbuk 38541, Korea; 이이.org/0000-0002-89219062; Email: yoon@yu.ac.kr

Andrés. F. Gualdrón-Reyes - Institute of Advanced Materials (INAM), Universitat Jaume I (UJI), 12071 Castelló de la Plana, Castellón, Spain; Facultad de Ciencias, Instituto de Ciencias Químicas, Isla Teja, Universidad Austral de Chile, 5090000 Valdivia, Chile; 이이.org/0000-0002-02089235; Email: gualdron@uji.es, @GualdronReyes

Iván Mora-Seró - Institute of Advanced Materials (INAM), Universitat Jaume I (UJI), 12071 Castelló de la Plana,
Castellón, Spain; 이잉.org/0000-0003-2508-0994; Email: sero@uji.es, @IvanMoraSero

\section{Authors}

ChaeHyun Lee - Department of Chemistry, College of Natural Science, Yeungnam University, Gyeongsan, Gyeongbuk 38541, Korea

YeJi Shin - Department of Chemistry, College of Natural Science, Yeungnam University, Gyeongsan, Gyeongbuk 38541, Korea

Alexis Villanueva-Antolí - Institute of Advanced Materials (INAM), Universitat Jaume I (UJI), 12071 Castelló de la Plana, Castellón, Spain

Samrat Das Adhikari - Institute of Advanced Materials (INAM), Universitat Jaume I (UJI), 12071 Castelló de la Plana, Castellón, Spain; 이이.org/0000-0002-56705179

Jhonatan Rodriguez-Pereira - Center of Materials and Nanotechnologies, Faculty of Chemical Technology, University of Pardubice, 53002 Pardubice, Czech Republic; Central European Institute of Technology, Brno University of Technology, 61200 Brno, Czech Republic; o orcid.org/ 0000-0001-6501-9536

Jan M. Macak - Center of Materials and Nanotechnologies, Faculty of Chemical Technology, University of Pardubice, 53002 Pardubice, Czech Republic; Central European Institute of Technology, Brno University of Technology, 612 00 Brno, Czech Republic; 10 orcid.org/0000-0001-70913022

Camilo A. Mesa - Institute of Advanced Materials (INAM), Universitat Jaume I (UJI), 12071 Castelló de la Plana, Castellón, Spain; 이이.org/0000-0002-8450-2563

Sixto Giménez - Institute of Advanced Materials (INAM), Universitat Jaume I (UJI), 12071 Castelló de la Plana, Castellón, Spain

Complete contact information is available at: https://pubs.acs.org/10.1021/acs.chemmater.1c02772

\section{Author Contributions}

S.J.Y., A.F.G.-R., and I.M.-S. conceived the project. S.J.Y., S.D.A., and A.F.G.-R. designed the experiments. C.L., S.J.Y., and A.F.G.-R. synthesized PQDs and performed the corresponding morphological, structural, and optical properties. J.R.-P. and J.M.M. contributed to the XPS measurements and analysis. A.V. fabricated and characterized the LED devices. C.A.M. and S.G. performed the photocatalytic reactions. A.F.G.-R. coordinated the experimental work. I.M.S. coordinated the whole project. A.F.G.-R., S.J.Y., and I.M.-S. wrote the manuscript. All the authors contributed to the discussions.

\section{Notes}

The authors declare no competing financial interest.

\section{ACKNOWLEDGMENTS}

This work was supported by European Research Council (ERC) via Consolidator Grant (724424-No-LIMIT) Ministry of Science, Innovation of Spain under Projects STABLE (PID2019-107314RB-I00), ELECTROVAL (PID2020116093RB-C41),Generalitat Valenciana via Prometeo Grant Q-Devices (Prometeo/2018/098), UJI project (UJI-B202050), National Research Foundation of Korea (NRF) grant funded by the Korea government (MSIT) BK21 FOUR (Brain 
Korea 21 Four), 2019 R1F1A1062395 and 2021R1F1A1063382. The authors also thank the Ministry of Education, Youth and Sports of the Czech Republic for the financial support of XPS measurements using CEMNAT infrastructure (project LM 2018103). C.A.M. acknowledges the University Jaume I for the postdoc fellowship POSDOC/ $2019 / 20$.

\section{REFERENCES}

(1) Dey, A.; Ye, J.; De, A.; Debroye, E.; Ha, S. K.; Bladt, E.; Kshirsagar, A. S.; Wang, Z.; Yin, J.; Wang, Y.; Quan, L. N.; Yan, F.; Gao, M.; Li, X.; Shamsi, J.; Debnath, T.; Cao, M.; Scheel, M. A.; Kumar, S.; Steele, J. A.; Gerhard, M.; Chouhan, L.; Xu, K.; Wu, X.-g.; Li, Y.; Zhang, Y.; Dutta, A.; Han, C.; Vincon, I.; Rogach, A. L.; Nag, A.; Samanta, A.; Korgel, B. A.; Shih, C.-J.; Gamelin, D. R.; Son, D. H.; Zeng, H.; Zhong, H.; Sun, H.; Demir, H. V.; Scheblykin, I. G.; MoraSeró, I.; Stolarczyk, J. K.; Zhang, J. Z.; Feldmann, J.; Hofkens, J.; Luther, J. M.; Pérez-Prieto, J.; Li, L.; Manna, L.; Bodnarchuk, M. I.; Kovalenko, M. V.; Roeffaers, M. B. J.; Pradhan, N.; Mohammed, O. F.; Bakr, O. M.; Yang, P.; Müller-Buschbaum, P.; Kamat, P. V.; Bao, Q.; Zhang, Q.; Krahne, R.; Galian, R. E.; Stranks, S. D.; Bals, S.; Biju, V.; Tisdale, W. A.; Yan, Y.; Hoye, R. L. Z.; Polavarapu, L. State of the Art and Prospects for Halide Perovskite Nanocrystals. ACS Nano 2021, 15, 10775-10981.

(2) Du, X.; Wu, G.; Cheng, J.; Dang, H.; Ma, K.; Zhang, Y.-W.; Tan, P.-F.; Chen, S. High-quality $\mathrm{CsPbBr} 3$ perovskite nanocrystals for quantum dot light-emitting diodes. RSC Adv. 2017, 7, 10391-10396.

(3) Grisorio, R.; Di Clemente, M. E.; Fanizza, E.; Allegretta, I.; Altamura, D.; Striccoli, M.; Terzano, R.; Giannini, C.; Irimia-Vladu, M.; Suranna, G. P. Exploring the surface chemistry of cesium lead halide perovskite nanocrystals. Nanoscale 2019, 11, 986-999.

(4) Grisorio, R.; Fanizza, E.; Allegretta, I.; Altamura, D.; Striccoli, M.; Terzano, R.; Giannini, C.; Vergaro, V.; Ciccarella, G.; Margiotta, N.; Suranna, G. P. Insights into the role of the lead/surfactant ratio in the formation and passivation of cesium lead bromide perovskite nanocrystals. Nanoscale 2020, 12, 623-637.

(5) Gualdrón-Reyes, A. F.; Macias-Pinilla, D. F.; Masi, S.; Echeverría-Arrondo, C.; Agouram, S.; Muñoz-Sanjosé, V.; Rodríguez-Pereira, J.; Macak, J. M.; Mora-Seró, I. Engineering Srdoping for enabling long-term stable $\mathrm{FAPb} 1-\mathrm{xSrxI} 3$ quantum dots with $100 \%$ photoluminescence quantum yield. J. Mater. Chem. C 2021, 9, 1555-1566.

(6) Liu, F.; Zhang, Y.; Ding, C.; Kobayashi, S.; Izuishi, T.; Nakazawa, N.; Toyoda, T.; Ohta, T.; Hayase, S.; Minemoto, T.; Yoshino, K.; Dai, S.; Shen, Q. Highly Luminescent Phase-Stable CsPbI3 Perovskite Quantum Dots Achieving Near 100\% Absolute Photoluminescence Quantum Yield. ACS Nano 2017, 11, 10373-10383.

(7) Ding, C.; Liu, F.; Zhang, Y.; Hirotani, D.; Rin, X.; Hayase, S.; Minemoto, T.; Masuda, T.; Wang, R.; Shen, Q. Photoexcited hot and cold electron and hole dynamics at FAPbI3 perovskite quantum dots/ metal oxide heterojunctions used for stable perovskite quantum dot solar cells. Nano Energy 2020, 67, 104267.

(8) Gualdrón-Reyes, A. F.; Masi, S.; Mora-Seró, I. Progress in halideperovskite nanocrystals with near-unity photoluminescence quantum yield. Trends Chem. 2021, 3, 499-511.

(9) Protesescu, L.; Yakunin, S.; Bodnarchuk, M. I.; Krieg, F.; Caputo, R.; Hendon, C. H.; Yang, R. X.; Walsh, A.; Kovalenko, M. V. Nanocrystals of Cesium Lead Halide Perovskites (CsPbX3, X $=\mathrm{Cl}$, $\mathrm{Br}$, and I): Novel Optoelectronic Materials Showing Bright Emission with Wide Color Gamut. Nano Lett. 2015, 15, 3692-3696.

(10) Nedelcu, G.; Protesescu, L.; Yakunin, S.; Bodnarchuk, M. I.; Grotevent, M. J.; Kovalenko, M. V. Fast Anion-Exchange in Highly Luminescent Nanocrystals of Cesium Lead Halide Perovskites (CsPbX3, X = Cl, Br, I). Nano Lett. 2015, 15, 5635-5640.

(11) Protesescu, L.; Yakunin, S.; Kumar, S.; Bär, J.; Bertolotti, F.; Masciocchi, N.; Guagliardi, A.; Grotevent, M.; Shorubalko, I.; Bodnarchuk, M. I.; Shih, C.-J.; Kovalenko, M. V. Dismantling the "Red Wall" of Colloidal Perovskites: Highly Luminescent Formami- dinium and Formamidinium-Cesium Lead Iodide Nanocrystals. ACS Nano 2017, 11, 3119-3134.

(12) Gualdrón-Reyes, A. F.; Yoon, S. J.; Barea, E. M.; Agouram, S.; Muñoz-Sanjosé, V.; Meléndez, Á. M.; Niño-Gómez, M. E.; MoraSeró, I. Controlling the Phase Segregation in Mixed Halide Perovskites through Nanocrystal Size. ACS Energy Lett. 2018, 4, 54-62.

(13) Hao, M.; Bai, Y.; Zeiske, S.; Ren, L.; Liu, J.; Yuan, Y.; Zarrabi, N.; Cheng, N.; Ghasemi, M.; Chen, P.; Lyu, M.; He, D.; Yun, J.-H.; Du, Y.; Wang, Y.; Ding, S.; Armin, A.; Meredith, P.; Liu, G.; Cheng, H.-M.; Wang, L. Ligand-assisted cation-exchange engineering for high-efficiency colloidal Cs1-xFAxPbI3 quantum dot solar cells with reduced phase segregation. Nat. Energy 2020, 5, 79-88.

(14) NREL, Best Research-Cell Efficiency Chart. https://www.nrel. gov/pv/assets/pdfs/best-research-cell-efficiencies-rev210726.pdf (accessed August 02, 2021).

(15) Lin, K.; Xing, J.; Quan, L. N.; de Arquer, F. P. G.; Gong, X.; Lu, J.; Xie, L.; Zhao, W.; Zhang, D.; Yan, C.; Li, W.; Liu, X.; Lu, Y.; Kirman, J.; Sargent, E. H.; Xiong, Q.; Wei, Z. Perovskite light-emitting diodes with external quantum efficiency exceeding 20 per cent. Nature 2018, 562, 245-248

(16) Kim, Y.-H.; Kim, S.; Kakekhani, A.; Park, J.; Park, J.; Lee, Y.-H.; Xu, H.; Nagane, S.; Wexler, R. B.; Kim, D.-H.; Jo, S. H.; MartínezSarti, L.; Tan, P.; Sadhanala, A.; Park, G.-S.; Kim, Y.-W.; Hu, B.; Bolink, H. J.; Yoo, S.; Friend, R. H.; Rappe, A. M.; Lee, T.-W. Comprehensive defect suppression in perovskite nanocrystals for high-efficiency light-emitting diodes. Nat. Photonics 2021, 15, 148155 .

(17) Zhang, Y.; Sun, R.; Ou, X.; Fu, K.; Chen, Q.; Ding, Y.; Xu, L.-J.; Liu, L.; Han, Y.; Malko, A. V.; Liu, X.; Yang, H.; Bakr, O. M.; Liu, H.; Mohammed, O. F. Metal Halide Perovskite Nanosheet for X-ray High-Resolution Scintillation Imaging Screens. ACS Nano 2019, 13, 2520-2525.

(18) Pradhan, B.; Das, S.; Li, J.; Chowdhury, F.; Cherusseri, J.; Pandey, D.; Dev, D.; Krishnaprasad, A.; Barrios, E.; Towers, A.; Gesquiere, A.; Tetard, L.; Roy, T.; Thomas, J. Ultrasensitive and ultrathin phototransistors and photonic synapses using perovskite quantum dots grown from graphene lattice. Sci. Adv. 2020, 6, No. eaay5225.

(19) Suárez, I.; Juárez-Pérez, E. J.; Bisquert, J.; Mora-Seró, I.; Martínez-Pastor, J. P. Polymer/Perovskite Amplifying Waveguides for Active Hybrid Silicon Photonics. Adv. Mater. 2015, 27, 6157-6162.

(20) Park, Y.-S.; Roh, J.; Diroll, B. T.; Schaller, R. D.; Klimov, V. I. Colloidal quantum dot lasers. Nat. Rev. Mater. 2021, 6, 382-401.

(21) Wu, J.; Tong, J.; Gao, Y.; Wang, A.; Zhang, T.; Tan, H.; Nie, S.; Deng, Z. Efficient and Stable Thin-Film Luminescent Solar Concentrators Enabled by Near-Infrared Emission Perovskite Nanocrystals. Angew. Chem. 2020, 132, 7812-7816.

(22) Albaladejo-Siguan, M.; Baird, E. C.; Becker-Koch, D.; Li, Y.; Rogach, A. L.; Vaynzof, Y. Stability of Quantum Dot Solar Cells: A Matter of (Life)Time. Adv. Energy Mater. 2021, 11, 2003457.

(23) Xue, J.; Lee, J.-W.; Dai, Z.; Wang, R.; Nuryyeva, S.; Liao, M. E.; Chang, S.-Y.; Meng, L.; Meng, D.; Sun, P.; Lin, O.; Goorsky, M. S.; Yang, Y. Surface Ligand Management for Stable FAPbI3 Perovskite Quantum Dot Solar Cells. Joule 2018, 2, 1866-1878.

(24) Zhang, Y.; Siegler, T. D.; Thomas, C. J.; Abney, M. K.; Shah, T.; De Gorostiza, A.; Greene, R. M.; Korgel, B. A. A “Tips and Tricks" Practical Guide to the Synthesis of Metal Halide Perovskite Nanocrystals. Chem. Mater. 2020, 32, 5410-5423.

(25) Buin, A.; Pietsch, P.; Xu, J.; Voznyy, O.; Ip, A. H.; Comin, R.; Sargent, E. H. Materials Processing Routes to Trap-Free Halide Perovskites. Nano Lett. 2014, 14, 6281-6286.

(26) Shen, X.; Zhang, Y.; Kershaw, S. V.; Li, T.; Wang, C.; Zhang, X.; Wang, W.; Li, D.; Wang, Y.; Lu, M.; Zhang, L.; Sun, C.; Zhao, D.; Qin, G.; Bai, X.; Yu, W. W.; Rogach, A. L. Zn-Alloyed CsPbI3 Nanocrystals for Highly Efficient Perovskite Light-Emitting Devices. Nano Lett. 2019, 19, 1552-1559.

(27) Zhang, L.; Kang, C.; Zhang, G.; Pan, Z.; Huang, Z.; Xu, S.; Rao, H.; Liu, H.; Wu, S.; Wu, X.; Li, X.; Zhu, Z.; Zhong, X.; Jen, A. K. Y. 
All-Inorganic CsPbI3 Quantum Dot Solar Cells with Efficiency over 16\% by Defect Control. Adv. Funct. Mater. 2021, 31, 2005930.

(28) Chen, C.; Xuan, T.; Bai, W.; Zhou, T.; Huang, F.; Xie, A.; Wang, L.; Xie, R.-J. Highly stable CsPbI3:Sr2+ nanocrystals with nearunity quantum yield enabling perovskite light-emitting diodes with an external quantum efficiency of 17.1\%. Nano Energy 2021, 85, 106033.

(29) Moyen, E.; Kanwat, A.; Cho, S.; Jun, H.; Aad, R.; Jang, J. Ligand removal and photo-activation of $\mathrm{CsPbBr} 3$ quantum dots for enhanced optoelectronic devices. Nanoscale 2018, 10, 8591-8599.

(30) Krieg, F.; Ong, Q. K.; Burian, M.; Rainò, G.; Naumenko, D.; Amenitsch, H.; Süess, A.; Grotevent, M. J.; Krumeich, F.; Bodnarchuk, M. I.; Shorubalko, I.; Stellacci, F.; Kovalenko, M. V. Stable Ultraconcentrated and Ultradilute Colloids of $\mathrm{CsPbX} 3(\mathrm{X}=\mathrm{Cl}$, $\mathrm{Br}$ ) Nanocrystals Using Natural Lecithin as a Capping Ligand. J. Am. Chem. Soc. 2019, 141, 19839-19849.

(31) Bodnarchuk, M. I.; Boehme, S. C.; ten Brinck, S.; Bernasconi, C.; Shynkarenko, Y.; Krieg, F.; Widmer, R.; Aeschlimann, B.; Günther, D.; Kovalenko, M. V.; Infante, I. Rationalizing and Controlling the Surface Structure and Electronic Passivation of Cesium Lead Halide Nanocrystals. ACS Energy Lett. 2018, 4, 63-74.

(32) Krieg, F.; Ochsenbein, S. T.; Yakunin, S.; ten Brinck, S.; Aellen, P.; Süess, A.; Clerc, B.; Guggisberg, D.; Nazarenko, O.; Shynkarenko, Y.; Kumar, S.; Shih, C.-J.; Infante, I.; Kovalenko, M. V. Colloidal CsPbX3 ( $\mathrm{X}=\mathrm{Cl}, \mathrm{Br}, \mathrm{I})$ Nanocrystals 2.0: Zwitterionic Capping Ligands for Improved Durability and Stability. ACS Energy Lett. 2018, 3, 641-646.

(33) Lu, M.; Guo, J.; Lu, P.; Zhang, L.; Zhang, Y.; Dai, Q.; Hu, Y.; Colvin, V. L.; Yu, W. W. Ammonium Thiocyanate-Passivated CsPbI3 Perovskite Nanocrystals for Efficient Red Light-Emitting Diodes. J. Phys. Chem. C 2019, 123, 22787-22792.

(34) Ahmed, T.; Seth, S.; Samanta, A. Boosting the Photoluminescence of $\mathrm{CsPbX} 3(\mathrm{X}=\mathrm{Cl}, \mathrm{Br}, \mathrm{I})$ Perovskite Nanocrystals Covering a Wide Wavelength Range by Postsynthetic Treatment with Tetrafluoroborate Salts. Chem. Mater. 2018, 30, 3633-3637.

(35) Mondal, N.; De, A.; Samanta, A. Achieving Near-Unity Photoluminescence Efficiency for Blue-Violet-Emitting Perovskite Nanocrystals. ACS Energy Lett. 2018, 4, 32-39.

(36) Milstein, T. J.; Kroupa, D. M.; Gamelin, D. R. Picosecond Quantum Cutting Generates Photoluminescence Quantum Yields Over $100 \%$ in Ytterbium-Doped $\mathrm{CsPbCl} 3$ Nanocrystals. Nano Lett. 2018, 18, 3792-3799.

(37) Di Stasio, F.; Christodoulou, S.; Huo, N.; Konstantatos, G. Near-Unity Photoluminescence Quantum Yield in CsPbBr3 Nanocrystal Solid-State Films via Postsynthesis Treatment with Lead Bromide. Chem. Mater. 2017, 29, 7663-7667.

(38) Nenon, D. P.; Pressler, K.; Kang, J.; Koscher, B. A.; Olshansky, J. H.; Osowiecki, W. T.; Koc, M. A.; Wang, L.-W.; Alivisatos, A. P. Design Principles for Trap-Free CsPbX3 Nanocrystals: Enumerating and Eliminating Surface Halide Vacancies with Softer Lewis Bases. J. Am. Chem. Soc. 2018, 140, 17760-17772.

(39) Yong, Z.-J.; Guo, S.-Q.; Ma, J.-P.; Zhang, J.-Y.; Li, Z.-Y.; Chen, Y.-M.; Zhang, B.-B.; Zhou, Y.; Shu, J.; Gu, J.-L.; Zheng, L.-R.; Bakr, O. M.; Sun, H.-T. Doping-Enhanced Short-Range Order of Perovskite Nanocrystals for Near-Unity Violet Luminescence Quantum Yield. J. Am. Chem. Soc. 2018, 140, 9942-9951.

(40) Ahmed, G. H.; El-Demellawi, J. K.; Yin, J.; Pan, J.; Velusamy, D. B.; Hedhili, M. N.; Alarousu, E.; Bakr, O. M.; Alshareef, H. N.; Mohammed, O. F. Giant Photoluminescence Enhancement in $\mathrm{CsPbCl} 3$ Perovskite Nanocrystals by Simultaneous Dual-Surface Passivation. ACS Energy Lett. 2018, 3, 2301-2307.

(41) Das Adhikari, S.; Behera, R. K.; Bera, S.; Pradhan, N. Presence of Metal Chloride for Minimizing the Halide Deficiency and Maximizing the Doping Efficiency in $\mathrm{Mn}$ (II)-Doped $\mathrm{CsPbCl} 3$ Nanocrystals. J. Phys. Chem. Lett. 2019, 10, 1530-1536.

(42) Stamplecoskie, K. G.; Manser, P. V. Dual nature of the excited state in organic-inorganic lead halide perovskites. Energy Environ. Sci. 2015, 8, 208-215.
(43) Yoon, S. J.; Stamplecoskie, K. G.; Kamat, P. V. How Lead Halide Complex Chemistry Dictates the Composition of Mixed Halide Perovskites. J. Phys. Chem. Lett. 2016, 7, 1368-1373.

(44) Masi, S.; Gualdrón-Reyes, A. F.; Mora-Seró, I. Stabilization of Black Perovskite Phase in FAPbI3 and CsPbI3. ACS Energy Lett. 2020, 5, 1974-1985.

(45) Hassanabadi, E.; Latifi, M.; Gualdrón-Reyes, A. F.; Masi, S.; Yoon, S. J.; Poyatos, M.; Julián-López, B.; Mora-Seró, I. Ligand \& Band Gap Engineering: Tailoring the Protocol Synthesis for Achieving High-Quality CsPbI3 Quantum Dots. Nanoscale 2020, 12, 14194-14203.

(46) Lee, C.; Shin, Y.; Jeon, G. G.; Kang, D.; Jung, J.; Jeon, B.; Park, J.; Kim, J.; Yoon, S. J. Cost-efficient, Effect of Low-Quality PbI2 Purification to Enhance Performances of Perovskite Quantum Dots and Perovskite Solar Cells. Energies 2021, 14, 201.

(47) Yakiangngam, J.; Monnoi, S.; Ruankham, P.; intaniwet, A.; Choopun, S. Optimization of a precursor-PbI2 layer by recrystallization for efficiency improvement in perovskite solar cells. Mater. Today: Proc. 2019, 17, 1210-1216.

(48) Zhang, Y.; Kim, S.-G.; Lee, D.-K.; Park, N.-G. CH3NH3PbI3 and $\mathrm{HC}(\mathrm{NH} 2) 2 \mathrm{PbI} 3$ Powders Synthesized from Low-Grade PbI2: Single Precursor for High-Efficiency Perovskite Solar Cells. ChemSusChem 2018, 11, 1813-1823.

(49) RSC. Golden Rain. https://edu.rsc.org/exhibition-chemistry/ golden-rain/2000048.article (accessed March 12, 2021).

(50) Park, Y. R.; Kim, H. H.; Eom, S.; Choi, W. K.; Choi, H.; Lee, B. $\mathrm{R}$; Kang, Y. Luminance efficiency roll-off mechanism in CsPbBr3$\mathrm{xClx}$ mixed-halide perovskite quantum dot blue light-emitting diodes. J. Mater. Chem. C 2021, 9, 3608-3619.

(51) Zhang, M.; Tian, Z.-Q.; Zhu, D.-L.; He, H.; Guo, S.-W.; Chen, Z.-L.; Pang, D.-W. Stable CsPbBr3 perovskite quantum dots with high fluorescence quantum yields. New J. Chem. 2018, 42, 9496-9500.

(52) Tao, S.; Schmidt, I.; Brocks, G.; Jiang, J.; Tranca, I.; Meerholz, K.; Olthof, S. Absolute energy level positions in tin- and lead-based halide perovskites. Nat. Commun. 2019, 10, 2560.

(53) Zhang, Q.; Nan, H.; Zhou, Y.; Gu, Y.; Tai, M.; Wei, Y.; Hao, F.; Li, J.; Oron, D.; Lin, H. In situ growth of $\alpha$-CsPbI3 perovskite nanocrystals on the surface of reduced graphene oxide with enhanced stability and carrier transport quality. J. Mater. Chem. C 2019, 7, 6795-6804.

(54) Zhao, Q.; Hazarika, A.; Schelhas, L. T.; Liu, J.; Gaulding, E. A.; Li, G.; Zhang, M.; Toney, M. F.; Sercel, P. C.; Luther, J. M. SizeDependent Lattice Structure and Confinement Properties in CsPbI3 Perovskite Nanocrystals: Negative Surface Energy for Stabilization. ACS Energy Lett. 2019, 5, 238-247.

(55) Wang, H.; Sui, N.; Bai, X.; Zhang, Y.; Rice, Q.; Seo, F. J.; Zhang, Q.; Colvin, V. L.; Yu, W. W. Emission Recovery and Stability Enhancement of Inorganic Perovskite Quantum Dots. J. Phys. Chem. Lett. 2018, 9, 4166-4173.

(56) Fu, Y.; Wu, T.; Wang, J.; Zhai, J.; Shearer, M. J.; Zhao, Y.; Hamers, R. J.; Kan, E.; Deng, K.; Zhu, X.-Y.; Jin, S. Stabilization of the Metastable Lead Iodide Perovskite Phase via Surface Functionalization. Nano Lett. 2017, 17, 4405-4414.

(57) Swarnkar, A.; Marshall, A. R.; Sanehira, E. M.; Chernomordik, B. D.; Moore, D. T.; Christians, J. A.; Chakrabarti, T.; Luther, J. M. Quantum dot-induced phase stabilization of $\alpha$-CsPbI3 perovskite for high-efficiency photovoltaics. Science 2016, 354, 92-95.

(58) Luo, C.; Li, W.; Xiong, D.; Fu, J.; Yang, W. Surface preoptimization of a mixed halide perovskite toward high photoluminescence quantum yield in the blue spectrum range. Nanoscale 2019, 11, 15206-15215.

(59) Shynkarenko, Y.; Bodnarchuk, M. I.; Bernasconi, C.; Berezovska, Y.; Verteletskyi, V.; Ochsenbein, S. T.; Kovalenko, M. V. Direct Synthesis of Quaternary Alkylammonium-Capped Perovskite Nanocrystals for Efficient Blue and Green Light-Emitting Diodes. ACS Energy Lett. 2019, 4, 2703-2711.

(60) Deepa, M.; Salado, M.; Calio, L.; Kazim, S.; Shivaprasad, S. M.; Ahmad, S. Cesium power: low Cs+ levels impart stability to perovskite solar cells. Phys. Chem. Chem. Phys. 2017, 19, 4069-4077. 
(61) Gualdrón-Reyes, A. F.; Rodríguez-Pereira, J.; Amado-González, E.; Rueda-P, J.; Ospina, R.; Masi, S.; Yoon, S. J.; Tirado, J.; Jaramillo, F.; Agouram, S.; Muñoz-Sanjosé, V.; Giménez, S.; Mora-Seró, I. Unravelling the Photocatalytic Behavior of All-Inorganic Mixed Halide Perovskites: The Role of Surface Chemical States. ACS Appl. Mater. Interfaces 2020, 12, 914-924.

(62) Han, R.; Zhao, Q.; Su, J.; Zhou, X.; Ye, X.; Liang, X.; Li, J.; Cai, H.; Ni, J.; Zhang, J. Role of Methyl Acetate in Highly Reproducible Efficient CsPbI3 Perovskite Quantum Dot Solar Cells. J. Phys. Chem. C 2021, 125, 8469-8478.

(63) Park, Y. R.; Eom, S.; Kim, H. H.; Choi, W. K.; Kang, Y. Selfdefect-passivation by Br-enrichment in FA-doped Cs1-xFAxPbBr3 quantum dots: towards high-performance quantum dot light-emitting diodes. Sci. Rep. 2020, 10, 14758.

(64) Soetan, N.; Puretzky, A.; Reid, K.; Boulesbaa, A.; Zarick, H. F.; Hunt, A.; Rose, O.; Rosenthal, S.; Geohegan, D. B.; Bardhan, R. Ultrafast Spectral Dynamics of $\mathrm{CsPb}($ BrxCl1-x)3 Mixed-Halide Nanocrystals. ACS Photonics 2018, 5, 3575-3583.

(65) Chirvony, V. S.; Sekerbayev, K. S.; Pashaei Adl, H.; Suárez, I.; Taurbayev, Y. T.; Gualdrón-Reyes, A. F.; Mora-Seró, I.; MartínezPastor, J. P. Interpretation of the photoluminescence decay kinetics in metal halide perovskite nanocrystals and thin polycrystalline films. J. Lumin. 2020, 221, 117092.

(66) Cardenas-Morcoso, D.; Gualdrón-Reyes, A. F.; Ferreira Vitoreti, A. B.; García-Tecedor, M.; Yoon, S. J.; Solis de la Fuente, M.; Mora-Seró, I.; Gimenez, S. Photocatalytic and Photoelectrochemical Degradation of Organic Compounds with All-Inorganic Metal Halide Perovskite Quantum Dots. J. Phys. Chem. Lett. 2019, 10, 630636.

(67) Salim, K. M. M.; Hassanabadi, E.; Masi, S.; Gualdrón-Reyes, A. F.; Franckevicius, M.; Devižis, A.; Gulbinas, V.; Fakharuddin, A.; Mora-Seró, I. Optimizing Performance and Operational Stability of $\mathrm{CsPbI} 3$ Quantum-Dot-Based Light-Emitting Diodes by Interface Engineering. ACS Appl. Electron. Mater. 2020, 2, 2525-2534.

(68) Lee, C.; Shin, Y.; Jeon, G. G.; Kang, D.; Jung, J.; Jeon, B.; Park, J.; Kim, J.; Yoon, S. J. Cost-efficient, Effect of Low-Quality PbI2 Purification to Enhance Performances of Perovskite Quantum Dots and Perovskite Solar Cells. Energies 2021, 14, 201.

(69) Huang, H.; Chen, X.; Huang, K. Preparation of PbI2 Microflakes by $\mathrm{pH}$-Controlled Double-Jet Precipitation. Open Chem. J. 2019, 6, 52-65. 